Review of Income and Wealth

Series 54, Number 2, June 2008

\title{
LIFETIMES OF MACHINERY AND EQUIPMENT: EVIDENCE FROM DUTCH MANUFACTURING
}

\author{
By Abdul Azeez Erumban* \\ Groningen Growth and Development Centre, Faculty of Economics, University of Groningen
}

\begin{abstract}
This paper estimates service lifetimes for capital assets in Dutch manufacturing industries, using information on asset retirement patterns. A Weibull distribution function is estimated using a nonlinear regression technique to derive service lifetimes for three selected asset types: transport equipment, machinery and computers. For this purpose, benchmark capital stock surveys for different two-digit industries are linked to annual discard surveys. On average the estimated lifetimes are 6,9 and 26 years for transport equipment, computers and machinery, respectively. However, these estimates vary across industries. A comparison of our estimates with Canadian, U.S. and Japanese estimates shows notable differences in the lifetimes of all the asset types, with machinery showing the largest difference.
\end{abstract}

\section{INTRODUCTION}

It is essential to have proper measures of inputs and output in order to unearth the contribution of inputs and productivity to output growth (see, for example, Jorgenson and Griliches, 1967, 1972; Denison, 1969). Consequently, accurate measurement of inputs, especially capital input and hence capital depreciation, has gained much attention in the economic literature (Jorgenson and Griliches, 1967; Hulten and Wykoff, 1981). Ever since the appearance of Goldsmith (1951), economists and statisticians have relied on capital stock data derived using the perpetual inventory method to illustrate changes in the productive contribution of capital. In the perpetual inventory method, the present capital stock is considered to be equal to the sum of past investment, after allowing for an "appropriate" depreciation rate. Therefore, depreciation measures assume vital importance in productivity analysis, especially multifactor productivity analysis using growth accounting, which depends, inter alia, on the growth of capital stock and capital services. ${ }^{1}$ Capital goods are viewed as carriers of capital services which

Note: This research builds upon earlier efforts within Statistics Netherlands (CBS) to study the issue of asset lifetimes. It could not have been undertaken without the help of many people at the CBS for which the author is grateful. In particular, discussions with George van Leeuwen, Mark de Haan and Gerard Meinen on different aspects of the data were very helpful. The suggestions and directions by Myriam Horsten in dealing with the capital stock and discard databases and the comments by Myriam, Dirk van den Bergen and Erik Veldhuizen on the paper were highly beneficial. Nevertheless, the views and results in the paper do not reflect the position of the CBS, and the author is solely responsible for the contents. The comments by Marcel Timmer, Bart Los and two anonymous referees are gratefully acknowledged.

*Correspondence to: Abdul Azeez Erumban, Faculty of Economics, University of Groningen, Post Bus 800, 9700AV, Groningen, the Netherlands (a.a.erumban@rug.nl).

${ }^{1}$ See Oulton (1995) for a discussion on the role of depreciation, obsolescence and capital in growth accounting. See also OECD (2001) for discussions on the concepts of depreciation, obsolescence, discards and lifetimes of capital.

(C) 2008 The Author

Journal compilation (C) 2008 International Association for Research in Income and Wealth Published by Blackwell Publishing, 9600 Garsington Road, Oxford OX4 2DQ, UK and 350 Main St, Malden, MA, 02148, USA. 
constitute the actual input in the production process. Therefore, if the depreciation of capital is not accurately measured, the estimated capital services and productivity will be biased. ${ }^{2}$ Recently there has been an urge towards inclusion of capital services into national accounts (Schreyer et al., 2005), further highlighting the need for better measures of depreciation. Furthermore, the recent revamping of an old debate on gross versus net concepts, both in terms of capital stock measurement as well as output in productivity and welfare analysis, signifies the importance of depreciation (Hulten, 2004; Oulton, 2004). Biørn et al. (1989) have empirically illustrated the importance of distinguishing between gross and net measures of capital stock. Similarly, it has been recently argued that net output is more appropriate for welfare analysis (Oulton, 2004). ${ }^{3}$ The difference between net and gross output (capital) is nothing but the depreciated amount of capital. Depreciation is also important in the macro economic and tax policy models, as tax policies related to depreciation allowances can have serious implications for incentives to invest in various types of assets (Coen, 1975; Hulten and Wykoff, 1981; Hwang, 2003).

Despite the growing importance of depreciation in economic measurement, empirical evidence on depreciation patterns is scarce. Geometric depreciation ${ }^{4}$ rates have been derived in the literature by using information on either used-asset prices (Hulten and Wykoff, 1981; Baldwin et al., 2005) or on asset lifetimes (Fraumeni, 1997; Hulten and Wykoff, 1981). Hulten and Wykoff (1981) have demonstrated how one can estimate depreciation using information on market prices (of used assets), based on microeconomics foundations. ${ }^{5}$ Nevertheless, this approach is feasible only if there is a substantial amount of information available on the used-asset prices. This is not true in most countries, with the possible exceptions of a few countries such as the United States and Canada. Therefore, researchers and national statistical institutes rely on estimates of lifetimes, and combine these with a particular depreciation pattern to derive depreciation rates. However, it is hard to find estimates of service lives derived using statistical information regarding the retiring pattern of capital assets. This is largely because firms do not have any incentive to keep a record of their asset discard, which makes it difficult to arrive at reliable estimates of asset lifetimes (West, 1998). Accountants often consider it bad practice to include discarded assets in balance sheets, as it may appear like fraud. The general practice of national statistical institutes is to rely on expert advice, information form tax authorities, or company records (OECD, 2001). These sources, however, may provide biased estimates of lifetimes. For instance, it is quite possible that the lifetimes and depreciation measures provided by tax authorities are manipulated for stimulating investment. This paper aims to analyze the discard pattern of capital assets to estimate expected lifetimes of these assets in the Netherlands, using information on directly observed capital stock and retirement patterns of assets. Information on actual retirement patterns assists in deri-

${ }^{2}$ For a detailed discussion on the components of capital service and their measurement, see Erumban (2007).

${ }^{3}$ See also Jorgenson and Griliches (1972), Denison (1985), Jorgenson (1989) and Fraumeni (1997).

${ }^{4}$ For a detailed discussion on various forms of depreciation patterns, see OECD (2001).

${ }^{5}$ The idea behind using used asset price models is that the component unit cost associated with the aging of assets, i.e. the depreciation, can be isolated by comparing prices of assets of different ages. See also Hwang (2003) and Baldwin et al. (2005) for two recent studies along these lines. 


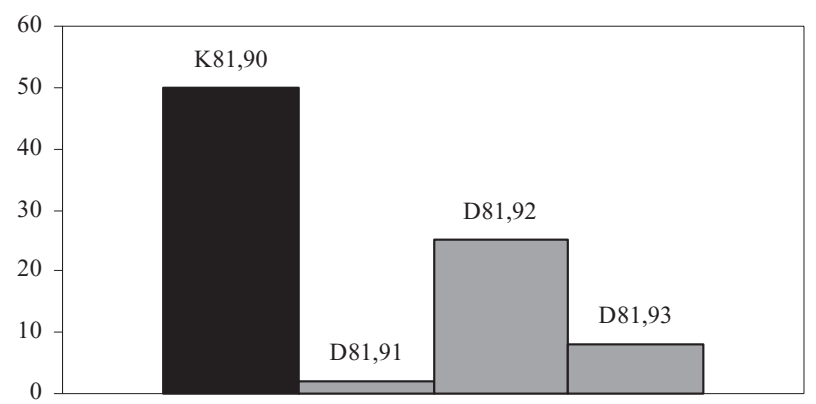

Figure 1. Benchmark capital stock (K) and annual discard series (D) of vintage $j$ in year $t$ Notes: $\mathrm{K}(\mathrm{D})^{*}{ }^{* *}=$ capital stock $($ Discard) of vintage $*$ existed in year $* *$.

vation of the expected service lives of assets. Statistics Netherlands (CBS) is one of the few statistical agencies in the world which collects data on capital stock and discards on a continuous basis (Smeets and van den Hove, 1997; Meinen, 1998). These two databases - capital stock and discard - are used in combination to estimate the asset lifetimes for three asset types - transport equipment, computers and machinery - in different industrial sectors. The estimated lifetimes for the Netherlands are presented in comparison with estimates for the United States, Canada and Japan.

It may be noted that there have been attempts in the past to estimate the service lifetimes of capital assets in the Dutch manufacturing sector, utilizing the capital stock and discard data (Meinen, 1998; Meinen et al., 1998; Bergen et al., 2005). The present paper is an addition to these existing studies and differs from earlier work in its methodology. We feed more discard information into the estimation of lifetimes than before and hence provide better estimates. That is, we monitor the discard pattern of each vintage over three consecutive years, and consider the average pattern over three different vintages for a given age (see Section 2 for more detailed discussion). Earlier studies on Dutch manufacturing (Meinen, 1998; Meinen et al., 1998; Bergen et al., 2005) have considered only one vintage for a given age. Considering a single vintage as representative for a given age for all vintages may result in biased estimates if the selected vintage is not representative enough. Moreover, like investments, firm-level discards sometimes follow a spiky pattern with positive discards in one year, followed by zero discards in subsequent years. Therefore, a single discard year may not necessarily provide a good representation of actual discard pattern. This problem is eased, to some extent, in this study by analyzing more vintages for a single age, including discard data for up to 3 years, rather than 1 year (see Figure 1 and the following discussion in Section 3). Indeed, we observe that the estimated survival function fits better to actual data when we incorporate more discard information, thereby providing better parameter estimates.

The paper is organized in five sections. Section 2 presents the methodology used in the present study in estimating lifetimes of assets. Section 3 provides a discussion on data and variables and Section 4 provides the empirical results. Section 5 concludes the paper. 


\section{Estimating Survival Functions and Asset Lifetimes: The Methodology}

As mentioned earlier, we estimate service lifetime of assets using actual information on capital stock and discard, which can be used to derive estimates of depreciation. In order to derive consistent estimates of lifetime of capital assets, we analyze the discard pattern of these assets, which gives insights into the survival function. The survival function is the cumulative distribution of the probability that an asset survives until a given age and it helps us derive average service life of the capital asset.

While estimating the survival distribution, one faces the problem of selecting an appropriate functional form. There have been a number of approaches suggested in the literature on duration models to analyze survival functions. OECD (2001) has shown that most distributions except delayed linear and bell-shaped distributions are clearly unrealistic. ${ }^{6}$ Furthermore, earlier studies have emphasized that survival functions with longer tails, such as the Weibull or delayed linear functions, are more realistic (Meinen et al., 1998; OECD 2001). In most empirical studies, researchers generally opt to use an exponential or Weibull distribution for lifetime distribution. However, when the lifetime is assumed to be distributed according to the exponential distribution, then the hazard rate is a constant, independent of time. A constant hazard rate implies that the probability of scrapping during the next time interval does not depend upon the duration spent in the initial state (Verbeek, 2004). The Weibull distribution, on the other hand, does not assume a constant hazard rate (see Pitman, 1992) $;^{7}$ it is a parametric distribution which includes decreasing, constant and increasing hazard rates. The Weibull specification requires only two parameters; it also captures distributions that are skewed. Hence, in our estimation, in line with earlier studies (Meinen, 1998; Bergen et al., 2005; Nomura, 2005), we also assume a Weibull distribution to describe the discard pattern.

The Weibull distribution has two parameters, $\alpha$ and $\beta$, where the former is the shape parameter and the latter is the scale parameter. The lifetime distribution or the probability density (mortality) function, $f(x)$, of the Weibull can be written as:

$$
f(x)=\frac{\alpha}{\beta}\left(\frac{x}{\beta}\right)^{\alpha-1} e^{-\left(\frac{x}{\beta}\right)^{\alpha}} \quad \text { for } x \geq 0,
$$

where $x$ is the age of the asset. This function is helpful in calculating the percentage of asset of a given vintage that is discarded at different ages. The exponential distribution is a special case of Weibull where $\alpha$ takes the value 1 , hence a single parameter distribution with constant retirement. Thus Weibull is the exponential

\footnotetext{
${ }^{6}$ Other distributions include simultaneous exit and linear (see OECD, 2001). While the former assumes all the assets to be retired from capital stock at the moment they reach their average service life, the latter assumes that the surviving assets are reduced by a constant amount each year. The delayed linear is a variant of linear one in that it also assumes retirement of assets in equal parts until the entire vintage is fully scrapped, but the retirement starts later than in the linear case and finishes sooner. The bell-shaped distribution, on the other hand, assumes a gradual retirement which starts some years after the year of installation, reaches the maximum around its average service life, and then starts lowering some years after average lifetime.

${ }^{7}$ See also Bekker (1991) for a detailed discussion on the properties of Weibull distribution, and Mudholkar et al. (1996) for a generalized Weibull family of distributions for survival studies.
} 
distribution of the power transformed age, and is therefore more flexible than the exponential. From (1), the survival function $S(x)$ - the probability that an asset of any vintage survives until the age $x$ - can be written as $1-F(x)$, where $F(x)$ is the cumulative density function, i.e. the cumulative distribution of lifetime distribution $f(x)$, i.e.

$$
F(x)=\int_{0}^{x} f(y) d y=1-e^{-\left(\frac{x}{\beta}\right)^{\alpha}}
$$

and the survival function $S(x)$ is:

$$
S(x)=1-F(x)=e^{-\left(\frac{x}{\beta}\right)^{\alpha}}
$$

where $S(0)=1, S(\propto)=0$ and $S(1 / \lambda)=e^{-1}$, independently of the value of $\alpha$.

For notational simplicity assume $\lambda=1 / \beta$. Then introducing the additive error term $u$ with standard assumptions, one can specify an estimable non-linear equation, where survival function ${ }^{8}$ is a function of age, as:

$$
S(x)=e^{-(\lambda x)^{\alpha}}+u \text {. }
$$

Given the Weibull distribution parameters, $\alpha$ and $\lambda$, the $n$-th moment of Weibull probability density function is given by:

$$
\mu_{n}=\left(\frac{1}{\lambda}\right)^{n} \Gamma\left(1+\frac{n}{\alpha}\right)
$$

where $\Gamma(n)$ is the Gamma function of the shape parameter $n, \Gamma(n)=\int_{0}^{\infty} y^{n-1} e^{-y} d y$.

Following (5) the first moment or the mean of the two parameter Weibull, which is by definition the expected average service life (Bekker, 1991; Nomura, 2005), $E(x)$, is given by: ${ }^{9}$

$$
\mu_{1}=E(x)=\frac{1}{\lambda} \Gamma\left(1+\frac{1}{\alpha}\right)
$$

${ }^{8}$ Some previous studies have used hazard function instead of survival function to derive asset lifetimes (e.g. Meinen, 1998). Survival function and hazard rate are closely related concepts, the latter is nothing but a simple transformation of the former. The hazard function can be expressed as $h(x)=f(x) / S(x)$, where $f(x)$ is the lifetime distribution, and $S(x)$ is the survival function. The hazard function describes the conditional probability that the asset is scrapped at a given age, given that it has survived up to that age. For the Weibull it can be derived as $h(x)=\frac{\alpha \lambda(\lambda x)^{\alpha-1} e^{-(\lambda x)^{\alpha}}}{e^{-(\lambda x)^{\alpha}}}=\alpha \lambda(\lambda x)^{\alpha-1}$.

${ }^{9}$ The median and mode are respectively $1 / \lambda\left[(\ln 2)^{1 / \alpha}\right]$ and $1 / \lambda\left[(1-(1 / \alpha))^{1 / \alpha}\right]$. See Bekker $(1991)$ for a detailed discussion on the properties of Weibull distribution. 
TABLE 1

INDUSTRIES CONSIDERED IN THE STUdy

\begin{tabular}{ll}
\hline \hline ISIC & Industry \\
\hline $15+16$ & Food, beverages \& tobacco \\
$17-19$ & Textile \& leather products \\
$20+33+36$ & Wood \& wood products, medical \& optical \\
& equipment \& other manufacturing \\
& Paper and paper products \\
21 & Publishing and printing \\
22 & Petroleum products; cokes, and nuclear fuel \\
23 & Basic chemicals and man-made fibers \\
25 & Rubber and plastic products \\
26 & Other non-metallic mineral products \\
27 & Basic metals \\
28 & Fabricated metal products \\
29 & Machinery and equipment n.e.c. \\
$30+32$ & Office machinery \& computers, radio, TV \& \\
31 & communication equipment \\
$34+35$ & Electrical machinery n.e.c. \\
\hline
\end{tabular}

The values of $\alpha$ and $\lambda$ estimated using equation (4) are inserted in (6) to obtain the expected lifetime estimates of assets. ${ }^{10}$

\section{Data And Variables}

The survival function and asset lifetime estimation in this paper are conducted for 22 two-digit manufacturing industries in the Netherlands. However, in some cases several two-digit industries are combined, based on the technology/product characteristics of such industries. For instance, different two-digit groups under textile products are combined into one. This was done in order to ensure sufficient numbers of observations to perform the regression analysis. Two exceptions are wood \& wood products and medical \& optical equipment. Due to the very low number of observations in these industries, we had to combine them with other industries group despite having no common technological/product characteristics. Effectively, we have 15 industry groups in the final sample. Table 1 presents the list of industries considered in the present study along with the corresponding ISIC codes. The data are taken from two distinctive micro-economic surveys conducted by Statistics Netherlands (CBS) — the capital stock survey and the discard survey. Therefore, it was essential to link these two to construct a comparable database. ${ }^{11}$ We briefly discuss these two surveys below.

${ }^{10}$ Note that it is also possible to derive service lifetime of capital assets by monitoring the lifetime of various vintages - the difference between the purchase year and discard year for each vintage will provide the lifetime of that particular vintage, and an average across various vintages for a given asset will provide the mean service life for any given asset. However, given the nature of our dataset, it is not possible to perform such an analysis, as it requires information on the year in which the asset is fully scrapped. Our data provide only the portion of each cohort of a particular vintage that is scrapped in a particular year; hence we need to go for a probability function.

${ }^{11}$ See Bergen et al. (2005) and Meinen (1998) for previous studies that have used these surveys in combination. 
The capital stock surveys have been conducted on a rolling basis since 1993 in such a way that each two-digit industry will be surveyed once in five years. ${ }^{12}$ The survey contains information on all fixed assets that are used by enterprises in their production process, whether the assets are owned, rented or obtained through a leasing contract. More importantly, it provides the vintage year of each asset. ${ }^{13}$ Because of its rolling nature, one or two benchmarks are available for each two-digit industry during the period 1993-2001. Therefore it was essential to consider one benchmark year for each industry and match it with subsequent discard years.

The data on discards ${ }^{14}$ in the manufacturing industry has been collected since 1992 in the Netherlands (see Smeets and van den Hove, 1997). The survey provides information on all fixed assets which are no longer used in the production process. That is, it comprises all capital goods removed from the production process during the course of a particular year. However, this data is quite limiting due to the low response rate to this survey, as the information is gathered through mailed questionnaires. ${ }^{15}$ The information available includes the value of asset withdrawn from the production process both in historic and current prices, and the destination to which the withdrawn asset goes to, i.e. whether the asset is scrapped, sold in the second-hand market or returned to the lease company (the last option was added only recently).

Both capital stock and discard surveys cover only firms with 100 employees or more. ${ }^{16}$ They provide firm level information on these variables in historic price at different vintages for eight asset types (see Appendix), among which we consider three: external transport equipment; machinery and equipment, including internal means of transport (excluding computers); and computers and associated equipment (data processing machines that are freely programmable, including peripheral devices - computers, printers, etc).

Appendix Tables A1 and A2 show the number of firms reported to various benchmark capital stock surveys and annual discard surveys during 1993-2001. There are 1354 manufacturing firms that have responded to at least one benchmark capital stock survey and a maximum of 1245 firms that have responded to various discard surveys during 1994-2001. Nevertheless, we have not included all these firms in our final dataset as we had to delete a number of firms during the cleaning process. Since our methodology to estimate asset lifetimes includes the use

\footnotetext{
${ }^{12}$ See Lock (1985) for a documentation of the experiment by the CBS to arrive at directly observed measures of capital stock.

${ }^{13}$ In some cases, especially for very old vintages, the exact year in which the asset was purchased is not available. But there is an average range of period available for such vintages, and hence the mid year is selected as the vintage year. Also, it is not clear whether the vintage years reported by firms for assets which are leased or purchased in the second-hand market are exact vintage years. For instance, they could be the year in which the firm has bought the asset in the second-hand market. Nevertheless, the presence of such cases is significant only in asset type transport equipment.

${ }^{14}$ Discards are also known as disinvestments or the withdrawal of assets from the production process. We use the concept "discard" throughout this paper.

${ }^{15}$ Nevertheless, the data are quite reliable as the reported information is subjected to further scrutiny and reconfirmation in cases which are unbelievable or where extreme information is found.

${ }^{16}$ Firms employing 100 or more employees constitute almost 69 percent of total employment, 80 percent of total sales and output and 78 percent of total value added in 2000, and therefore it is a fair sample of total manufacturing.
} 
of both capital stock and discard data, we have created a combined dataset, consisting of firms reporting in capital stock and discard surveys.

The historic value of capital stock in year $t-1$ (as on December 31) is linked to the historic value of discards in years $t, t+1$ and $t+2$ for each firm. Earlier studies have linked the benchmark capital stock in year $t-1$ to only one discard year, say $t$, as they have used only single year discard information in the estimation of lifetimes (Bergen et al., 2005). As mentioned above, in contrast to earlier studies, the present study intends to incorporate more discard information into the estimation of lifetimes. Hence the benchmark capital stock data is linked to three discard years. The data is linked for each asset type and vintage year. That is, the capital stock data for a particular asset bought in a particular year is linked to the same firm's discard data for the same asset type of the same vintage. In the next step, we have deleted all the firms that have not reported to capital stock surveys, but to the discard surveys. This is because, since our analysis requires estimates of survival rates, which are the percentage of capital survived over years, it is meaningful only to include those firms that have reported to capital stock surveys. Also, all those firms that have not reported discard value for at least one vintage are dropped from the sample. That is, even if a firm has reported discards only in $n$ vintages with reported capital stock in more than $n$ vintages it is included in the sample. For the reported vintages, the actual discard values are used, while for the non-reported vintages, the discard is assumed to be zero. This assumption is based on the premise that there is no reason for a firm to report discard in certain vintages while not report discard in other vintages, other than not having a discard in that particular vintage. Those firms that have no reported discard value in any vintage are dropped, as we do not have any idea whether they have made any positive discard or not. Their inclusion may result in an exaggeration of capital stock, if we attribute zero discards to such firms. Such an attempt is seen to produce strange results, exaggerating the lifetimes of capital assets.

All cases where the reported discard values are higher than the capital in the given vintage are deleted from the sample. ${ }^{17}$ All other cases (i.e. discard just equal to capital stock, where we assume a full discard of the asset; discard is zero, where we assume the entire capital is survived; and the discard is less than capital stock) are included in the sample. Thus finally we have a sample in which the number of firms is much lower than the actual number of responding firms. We end up with 969 firms (72 percent of total firms reported to various capital stock surveys) when we link the capital stock in year $t-1$ to the discard in year $t$ which has further declined to 592 (44 percent) when two more discard years have been added (i.e. when we consider three discard years, $t$ and $t+1$ and $t+2$ ). This decline is to be expected because in the first case we include all those firms that have reported at least one vintage discard in the first year; however, in the second case they are included in the sample only if they have responded to discard surveys in the second and third years. This decline in the number of firms, however, is observed to have

\footnotetext{
${ }^{17}$ While excluding such firms, we have allowed for a margin of error of 2 percent. That is, even if the discard is greater than capital by 2 percent of capital at firm level, we have included them, assuming that it will be a reporting error. However, they are subjected to further scrutiny in that if the discard is greater than capital stock even after aggregating to industry level (for each vintage), we drop such cases from the original sample.
} 
only a marginal effect on the number of observation (vintages) in our regression analysis. The final sample consists of 53 percent of total firms reported to the first discard year survey and 52 percent of firms reported during three consecutive discard surveys. As previously mentioned, for most industries there are two benchmark capital stock surveys available (see Appendix, Table A1). However, we have considered only the first round benchmark surveys in the current analysis; the second round will not allow us to include up to three discard years, as the discard data is not available since 2001. This is also the reason why we limit the number of discard years to three; the recent benchmarks do not allow us to use more than three discard years.

We have aggregated this linked dataset to the two-digit industry level across each vintage for each asset separately. This aggregation is performed in order to ensure a sufficient number of firms in the sample. This leaves us with the final dataset for each two-digit industry, for different asset types and vintages. In our regression analysis, for each asset type, the degrees of freedom will be the number of vintages in that particular asset rather than the number of firms. Therefore, as mentioned before, the decline in the number of firms caused by the inclusion of more discard years into the model has only a negligible effect on the degrees of freedom in our regression model. For each industry we have a series of data on historic value of capital stock and discards across various vintage years, which is used to construct the variables entering to our regression equation in (4). In what follows we explain each of the variables and their construction.

Survival function $(S)$ : The dependent variable in our Weibull specification (4) is the survival function, which is calculated as the cumulative distribution of survival rate. It implies the probability that an asset is not discarded before age $x$. In order to calculate survival rate we exploit data on capital stock and discard. Capital stock is the historic value of asset $i$ of vintage $j$ for industry $k$, taken as such from the capital stock survey, and discard is the historic value of asset $i$ of vintage $j$ for industry $k$, taken from the discard survey. The survival rate for a particular asset of particular vintage $j$ at time $t$ (or at age $x$ where $x$ is measured as $t-j$ ), is calculated as the historic value of capital in year $t-1$ minus historic value of discard in year $t$ divided by historic value of capital in year $t-1$. Specifically, provided that the benchmark capital stock is available for the year $t-1$ and discard data is available for the year $t$, the survival rate for an asset of age $x$ in year $t$ can be calculated as: ${ }^{18}$

$$
s_{j}^{t}(x)=\frac{K_{j, t-1}-D_{j, t}}{K_{j, t-1}}
$$

where $s_{j}^{t}(x)$ is the survival rate of an asset of vintage $j$ at age $x$ at time $t$. The age of an asset of a particular vintage is calculated as the discard year (year when it was discarded) minus its vintage year (year when it was purchased); i.e. $x=t-j . K$ is the historic value of capital stock and $D$ is the historic value of discard of an asset of $j$-th vintage in year $t$. Since we use both capital stock and discard of same vintage to derive survival rates, we consider them in historic prices. The results will remain

\footnotetext{
${ }^{18}$ For simplicity the industry index $(k)$ is dropped.
} 
the same even if we use current or constant price figures, as both these variables will be inflated (deflated) by the same price indices, and as we take the ratios. Assuming that the survival rates for an asset of all vintages are equal for a given age $x$, i.e. $s_{j}(x)=s(x)$, (7) provides us with the probability that an asset of any vintage survives until age $x$, under the condition that it has survived until age $x-1$. This is a standard, but strong, assumption, needed to make empirical estimation possible with the available data. Otherwise, one requires obtaining the information on capital stock and discards in all vintages over a long span of time, which is not practically possible. The capital that is reported in year $t-1$ is assumed to be the capital as existed on December 31 in year $t-1$; therefore, $D_{j}$ for year $t-1$ in (7) is assumed to be zero.

As mentioned earlier, the discard data is quite limiting as the response rate is low. Moreover, the discard pattern was found to be lumpy in most cases, as is the investment. An imaginary example of lumpy discard is depicted in Figure 1. The first bar in the figure shows the capital stock of vintage 1981 which existed in the year 1990 (that is, of age 9), and the second, third and fourth bars respectively show the value of discarded capital of the same vintage in years 1991, 1992 and 1993 (that is, at age 10, 11 and 12). It is obvious from the figure that the discard pattern is lumpy, with almost no discard at age 10 and a large amount of discard at age 11. However, if we consider the total discard over the three consecutive years, we see that almost 70 percent of capital is discarded during the three years. According to the abovementioned methodology, the first two bars can be used to calculate the survival rate of an asset of age 10. Following the assumption $s_{j}(x)=s(x)$, the survival rate calculated using the first two bars can be considered representative of the survival rate of asset of any vintage at age 10 . Hence, as we observe very low discard in the first year, which will result in a very high survival rate at age 10, attributing the same survival rate calculated using a single year's discard information (as in (7)) for all vintages does not seem to be appropriate. Though the particular vintage, considered as the representative vintage for the given age, say 10, has shown such a tendency, it may not hold for all vintages. Moreover, the same vintage has shown a bulky discard in the next year, indicating that considering a single discard pattern may result in a biased estimate of survival rate. Therefore, if one considers the single year discard information, taking a single vintage as representative of a particular age may affect the estimated survival rate for that particular age for all vintages, if the representative vintage has shown a very large or small discard.

It can be argued that this lumpiness may disappear in some cases, when aggregating across vintages at the two-digit industry level. However, the problem of considering a single vintage as representative for all vintages at a given age still prevails. It is not necessary that all vintages have a similar discard behavior at any given age. That is, as mentioned earlier, the assumption of $s_{j}(x)=s(x)$ need not hold in a complete sense. For instance, the survival pattern of an asset of age 10 of vintage 1997 may be different from an asset of age 10 of vintage 1999. However, in order to incorporate this heterogeneity completely into the model, as we stated before, we need to have discard information throughout the lifetime of each asset, which is not practically possible. Therefore, given the data constraints, we suggest examining more vintages for the same age and consider an aggregate or average 
discard behavior of these different vintages at any particular age. In doing this we have considered three discard years for each vintage, which will help us calculate the survival rate for a particular vintage at three different ages. This will help us make the assumption $s_{j}(x)=s(x)$ less strong, though not completely relaxed. Thus, unlike the earlier studies (Bergen et al., 2005), which consider only the first year discard information, the present approach has the advantage of feeding more information on discard pattern of different vintages into the estimation of lifetime. More specifically, assuming that there is no second-hand investment in any particular asset of a given vintage, the survival rate for any particular asset of age $x$ in years $t+1$ and $t+2$ is given by:

$$
\begin{gathered}
s_{j+1}^{t+1}(x)=\frac{K_{j+1, t-1}-D_{j+1, t}-D_{j+1, t+1}}{K_{j+1, t-1}-D_{j+1, t}} \\
s_{j+2}^{t+2}(x)=\frac{K_{j+2, t-1}-D_{j+2, t}-D_{j+2, t+1}-D_{j+2, t+2}}{K_{j+2, t-1}-D_{j+2, t}-D_{j+2, t+1}} .
\end{gathered}
$$

As before, we assume that $s_{j}(x)=s(x)$ for all vintages, i.e. survival rate for any given age is constant over time, but less strong. The assumption is less strong because the current approach incorporates more information on the discard behavior of firms at each age. This is because, when we take into account only one year of discard data, our estimate of the survival rate of a particular asset (say machinery), of a particular age (say 10 years) in a given industry, would be based only on the discards of machinery of vintage $j$ in year $j+10$. However, by also considering discards in years $j+11$ and $j+12$, the survival rate of age 10 is also based on observations of vintage $j+1$ and $j+2$, discarded in respectively $j+11$ and $j+12$. Then we take an average of these three survival rates for a given age as our preferred survival rate, which contains information of three different vintages for the given age. ${ }^{19}$ This average survival rate provides us with the survival rate of an asset of a specific age regardless of its vintage.

Note that (8) assumes that there is no second-hand investment in the vintage $j$. This is because, only in the absence of second-hand investment can capital stock in year $t$ for any particular vintage $j$ be calculated using information on capital stock in year $t-1$ and discard in year $t$ as $K_{j, t-1}-D_{j, t}$. If there exists second-hand investments in the given vintage $j$, the capital stock in year $t$ will be $K_{j, t-1}-D_{j, t}+S K_{j, t}$, where $S K_{j, t}$ is the second-hand purchases of the same vintage $j$. Hence the survival rate will be higher than what is actually obtained, assuming there is no second-hand investment. We do not attribute much significance to this

${ }^{19} \mathrm{We}$ have also calculated the survival rate using the total capital stock in three years $(t-1, t$ and $t+1)$ and total discards in three years $(t, t+1$ and $t+2)$. The total capital stock is calculated by summing the constant price capital stock at any given age, say $x$, existing during three years, where the annual capital stock is calculated as the difference between the previous year's capital stock and the current year's discard. Similarly the total discard at any given age is calculated by summing the three years constant price discard for the given age. Then the survival rate at age $x$ is calculated as the total capital stock of age $x$ during the three years $(t-1, t$ and $t+1)$ - total discards of age $x$ during the three years $(t, t+1$ and $t+2) /$ total capital stock of age $x$ during the three years $(t-1, t$ and $t+1)$. The results are similar to the ones obtained using average survival rates. 
problem, as it is expected to have only a negligible effect on our results; secondhand investments typically constitute a very tiny portion of total investment, especially in the asset types which we consider. For instance, from the recent investment surveys we gauge that the share of second-hand investment is only 1.5 percent in transport equipment, 0.3 percent in computers and 0.4 percent in machinery. This however varies across industries, with a maximum of 4 percent in all the asset types, and a mode of 0 in computers and machinery and 2.5 in transport equipment. Hence, our assumption that its share is trivial is justified (see Appendix, Table A3).

Once the survival rate is calculated, the survival function $(S)$ is calculated as the cumulative distribution of survival rates. That is,

$$
S(x)=\prod_{i=1}^{x} s(i)
$$

\section{EMPIRICAL RESUlts}

We have estimated equation (4), where we regresses the actual survival function, calculated using (9), on the age of the asset. Since the Weibull specification is non-linear in parameters, we have used a non-linear regression method. It is, however, possible to estimate the equation using a linear model by transforming the data into log form (e.g. Meinen, 1998). Nevertheless, the non-linear estimation is assumed to be more realistic and robust. In the linear transformed model, the parameter values are determined in such a way that they minimize the squared residuals for the transformed function rather than the original function. Hence, the estimated parameters may not produce the best fit of the original function to the data. Comparisons of estimated survival function with actual survival data have shown that the non-linear results are more close to actual data, compared to the linear ones (see Appendix, Figure A1). Hence, we opt for non-linear regression estimation using a sequential quadratic programming algorithm, as provided in SPSS. The estimation is performed both for a single discard year as well as the three discard years case for the purpose of comparison. In the former case, all firms that have reported at least one vintage in the first discard year are included in the sample, while in the latter case only firms that have reported zero or positive discard in at least one vintage in all the three years are included. The estimated parameters $\alpha$ and $\lambda$ are then used to derive the expected service lifetimes of capital, using equation (6). While performing the regression, we have faced the problem of exaggerated tails, caused by the continuous lack of discard reporting in some of the older vintages. Such longer tails affect the variability and hence the regression estimation. Therefore, we have excluded such large tails from our regression, after allowing for a maximum of three vintages after the oldest vintage with positive discard.

Tables 2, 3 and 4 provide the estimated coefficients of non-linear regression, using three years' discard information. The same for single year discard cases are provided in Appendix Tables A4, A5, and A6. It may be noted that there are three possibilities regarding the survival rate and consequently the shape parameter $\alpha$ 
TABLE 2

Estimated Regression Coefficients: Transport Equipment (3 Years Discard)

\begin{tabular}{lcccccccccc}
\hline \hline ISIC & $\alpha$ & SE & LC & UC & $\lambda$ & SE & LC & UC & R $^{2}$ & DF \\
\hline $15+16$ & 1.14 & 0.03 & 1.08 & 1.21 & 0.15 & 0.002 & 0.15 & 0.16 & 0.994 & 28 \\
$17-19$ & 1.00 & 0.17 & 0.63 & 1.37 & 0.16 & 0.016 & 0.12 & 0.19 & 0.856 & 17 \\
$20+33+36$ & 1.22 & 0.13 & 0.94 & 1.49 & 0.18 & 0.010 & 0.15 & 0.20 & 0.937 & 17 \\
21 & 1.12 & 0.13 & 0.85 & 1.39 & 0.20 & 0.013 & 0.17 & 0.23 & 0.929 & 17 \\
22 & 2.18 & 0.18 & 1.81 & 2.55 & 0.23 & 0.006 & 0.22 & 0.24 & 0.983 & 20 \\
23 & 1.00 & 0.08 & 0.83 & 1.17 & 0.11 & 0.006 & 0.10 & 0.12 & 0.926 & 30 \\
24 & 1.00 & 0.11 & 0.77 & 1.23 & 0.08 & 0.005 & 0.07 & 0.09 & 0.843 & 23 \\
25 & 1.00 & 0.14 & 0.70 & 1.30 & 0.14 & 0.011 & 0.12 & 0.16 & 0.864 & 16 \\
26 & 1.16 & 0.16 & 0.82 & 1.50 & 0.20 & 0.016 & 0.17 & 0.24 & 0.899 & 19 \\
27 & 1.80 & 0.11 & 1.56 & 2.04 & 0.11 & 0.003 & 0.11 & 0.12 & 0.984 & 16 \\
28 & 1.27 & 0.12 & 1.02 & 1.52 & 0.19 & 0.009 & 0.17 & 0.21 & 0.953 & 20 \\
29 & 1.12 & 0.17 & 0.75 & 1.49 & 0.18 & 0.016 & 0.15 & 0.22 & 0.895 & 13 \\
$30+32$ & 1.38 & 0.11 & 1.14 & 1.61 & 0.21 & 0.009 & 0.20 & 0.23 & 0.968 & 22 \\
31 & 1.05 & 0.14 & 0.73 & 1.37 & 0.15 & 0.011 & 0.12 & 0.17 & 0.920 & 11 \\
$34+35$ & 1.00 & 0.11 & 0.78 & 1.22 & 0.12 & 0.007 & 0.11 & 0.14 & 0.904 & 16 \\
\hline
\end{tabular}

Notes: SE is the standard error of the estimate. LC and UC are respectively the lower and upper $95 \%$ confidence intervals and DF is the degrees of freedom. All the coefficients are significant at $1 \%$.

TABLE 3

Estimated Regression CoefFicients: Computers (3 Years Discard)

\begin{tabular}{lcccccccccr}
\hline \hline Industry & $\alpha$ & $\mathrm{SE}$ & $\mathrm{LC}$ & $\mathrm{UC}$ & $\lambda$ & $\mathrm{SE}$ & $\mathrm{LC}$ & $\mathrm{UC}$ & $\mathrm{R}^{2}$ & $\mathrm{DF}$ \\
\hline $15+16$ & 2.16 & 0.15 & 1.83 & 2.48 & 0.11 & 0.002 & 0.10 & 0.12 & 0.984 & 15 \\
$17-19$ & 2.98 & 0.41 & 2.09 & 3.88 & 0.10 & 0.003 & 0.09 & 0.11 & 0.968 & 14 \\
$20+33+36$ & 1.88 & 0.36 & 1.10 & 2.67 & 0.13 & 0.009 & 0.11 & 0.15 & 0.895 & 13 \\
21 & 1.46 & 0.14 & 1.15 & 1.76 & 0.13 & 0.005 & 0.12 & 0.14 & 0.961 & 13 \\
22 & 1.67 & 0.13 & 1.39 & 1.96 & 0.09 & 0.003 & 0.09 & 0.10 & 0.968 & 16 \\
23 & 1.00 & 0.08 & 0.82 & 1.18 & 0.10 & 0.004 & 0.09 & 0.10 & 0.943 & 14 \\
24 & 1.53 & 0.06 & 1.40 & 1.65 & 0.10 & 0.002 & 0.10 & 0.11 & 0.993 & 15 \\
25 & 3.04 & 0.62 & 1.69 & 4.38 & 0.10 & 0.005 & 0.09 & 0.11 & 0.892 & 14 \\
26 & 4.60 & 0.69 & 2.90 & 6.30 & 0.11 & 0.003 & 0.11 & 0.12 & 0.962 & 7 \\
27 & 2.13 & 0.13 & 1.87 & 2.39 & 0.06 & 0.001 & 0.06 & 0.06 & 0.978 & 24 \\
28 & 1.97 & 0.06 & 1.84 & 2.10 & 0.12 & 0.001 & 0.11 & 0.12 & 0.996 & 15 \\
29 & 2.06 & 0.09 & 1.86 & 2.25 & 0.13 & 0.002 & 0.12 & 0.13 & 0.995 & 14 \\
$30+32$ & 1.44 & 0.04 & 1.36 & 1.51 & 0.12 & 0.001 & 0.11 & 0.12 & 0.996 & 18 \\
31 & 1.91 & 0.22 & 1.44 & 2.39 & 0.10 & 0.004 & 0.09 & 0.11 & 0.945 & 15 \\
$34+35$ & 2.56 & 0.13 & 2.28 & 2.84 & 0.13 & 0.002 & 0.12 & 0.13 & 0.994 & 13 \\
\hline
\end{tabular}

Notes: SE is the standard error of the estimate. LC and UC are respectively the lower and upper $95 \%$ confidence intervals and DF is the degrees of freedom. All the coefficients are significant at $1 \%$.

(Bekker, 1991; Meinen, 1998; OECD, 2001). The first is an increasing survival rate or a decreasing chance of discard, leading to an $\alpha$ lying between 0 and 1 . The second is that of a constant survival rate, leading to a unitary $\alpha$. The third possibility is of a decreasing survival rate or an increasing chance of discard, resulting in an $\alpha$ lying between 1 and infinity. In this case, there are three subpossibilities: a linearly decreasing survival rate, leading to an $\alpha$ taking the value 2; a regressively decreasing survival rate, leading to an $\alpha$ lying between 1 and 2; and a survival rate that decreases at a progressive rate, leading to an $\alpha$ greater than 2 . The value of $\lambda$, the scale parameter, does not affect the shape of the survival rate; 
TABLE 4

Estimated Regression Coefficients: Machinery (3 Years Discard)

\begin{tabular}{|c|c|c|c|c|c|c|c|c|c|c|}
\hline Industry & $\alpha$ & SE & $\mathrm{LC}$ & $\mathrm{UC}$ & $\lambda$ & SE & $\mathrm{LC}$ & $\mathrm{UC}$ & $\mathrm{R}^{2}$ & $\mathrm{DF}$ \\
\hline $15+16$ & 1.540 & 0.030 & 1.480 & 1.601 & 0.032 & 0.000 & 0.032 & 0.033 & 0.993 & 69 \\
\hline 17 to 19 & 1.705 & 0.047 & 1.610 & 1.800 & 0.039 & 0.000 & 0.038 & 0.040 & 0.989 & 54 \\
\hline $20+33+36$ & 1.571 & 0.074 & 1.421 & 1.720 & 0.036 & 0.001 & 0.035 & 0.037 & 0.966 & 48 \\
\hline 21 & 1.434 & 0.031 & 1.372 & 1.496 & 0.040 & 0.000 & 0.040 & 0.041 & 0.992 & 49 \\
\hline 22 & 2.001 & 0.092 & 1.814 & 2.188 & 0.065 & 0.001 & 0.063 & 0.067 & 0.985 & 34 \\
\hline 23 & 1.307 & 0.138 & 1.030 & 1.583 & 0.026 & 0.001 & 0.023 & 0.028 & 0.795 & 54 \\
\hline 24 & 1.721 & 0.053 & 1.615 & 1.826 & 0.036 & 0.000 & 0.035 & 0.037 & 0.986 & 57 \\
\hline 25 & 1.339 & 0.032 & 1.275 & 1.404 & 0.031 & 0.000 & 0.031 & 0.032 & 0.990 & 44 \\
\hline 26 & 2.231 & 0.429 & 1.368 & 3.094 & 0.031 & 0.002 & 0.027 & 0.034 & 0.679 & 47 \\
\hline 27 & 2.321 & 0.055 & 2.210 & 2.431 & 0.027 & 0.000 & 0.027 & 0.027 & 0.992 & 55 \\
\hline 28 & 1.400 & 0.047 & 1.306 & 1.494 & 0.031 & 0.000 & 0.030 & 0.032 & 0.976 & 65 \\
\hline 29 & 1.064 & 0.047 & 0.969 & 1.159 & 0.050 & 0.001 & 0.047 & 0.052 & 0.957 & 49 \\
\hline $30+32$ & 1.398 & 0.011 & 1.375 & 1.421 & 0.055 & 0.000 & 0.054 & 0.055 & 0.999 & 65 \\
\hline 31 & 1.028 & 0.028 & 0.972 & 1.084 & 0.024 & 0.000 & 0.023 & 0.025 & 0.983 & 54 \\
\hline $34+35$ & 1.318 & 0.062 & 1.193 & 1.442 & 0.039 & 0.001 & 0.037 & 0.040 & 0.961 & 47 \\
\hline
\end{tabular}

Notes: SE is the standard error of the estimate. LC and UC are respectively the lower and upper $95 \%$ confidence intervals and DF is the degrees of freedom. All the coefficients are significant at $1 \%$.

it affects only the magnitude of the survival rate, independent of the value of $\alpha$. There is a negative relationship between the value of $\lambda$ and the magnitude of the survival rate; the larger the magnitude of $\lambda$, the smaller the magnitude of the survival rate.

We observe that on average the $\alpha$ values are 1.2 for transport equipment, 2.2 for computers and 1.6 for machinery. This indicates that the chance of discard is highest in computers, followed by machinery and transport equipment. This is largely consistent with earlier estimates for the Netherlands (e.g. Meinen, 1998; Bergen et al., 2005). ${ }^{20}$ However, the values vary notably across industries. In transport equipment, almost six industries have shown an $\alpha$ hovering around 1, indicating a constant risk of discard. In eight industries $\alpha$ lies between 1 and 2, indicating a near constant or regressively decreasing survival rate; and in one industry, petroleum, cokes \& nuclear fuel, it is greater than 2, indicating a progressively increasing discard rate. In computers, there is only one industry with unitary $\alpha$, i.e. the petroleum, cokes \& nuclear fuel industry. The value of $\alpha$ lies between 1 and 2 in seven industries showing a regressively increasing chance of discard. Also in seven industries $\alpha$ is greater than 2, indicating a progressively decreasing survival rate, with the largest magnitude being in publishing $\&$ printing and basic metals. The story of machinery seems to be some what similar to that of transport equipment; there are two industries with $\alpha$ close to unity, 11 industries with $\alpha$ between 1 and 2, and only two industries with $\alpha$ greater than 2. Thus the number of industries with progressively increasing rate of discard is larger in computers compared to machinery and transport equipment. While the largest number of industries with constant survival rate is observed in transport equipment, the lowest is found in computers. These observations are intuitively appeal-

${ }^{20}$ The average values of $\alpha$ in Meinen (1998) are 1.3, 2.1 and 1.5, and in Bergen et al. (2005) are 1.5, 1.7 and 1.8 respectively for transport equipment, computers and machinery. These are calculated from table 3-1 of Meinen (1998) and tables A2 to A4 of Bergen et al. (2005). 
ing as one would expect the chance of discard to be higher in the asset type computers, which is subject to severe technological obsolescence. However, the intensity of discard risk, as visible from the magnitude of the coefficient, varies across industries, which may be due to the differences in composition of computer assets in various industries. For instance, if the share of fast depreciating components is higher, then the discard rate in such industries may face an acceleration compared to other industries. Also it can be seen from the tables that the magnitude of $\lambda$ is generally lower in asset type machinery, compared to computers and transport equipment. This indicates that, in general, the magnitude of survival rate (discard rate) is higher (lower) in machinery compared to computers and transport equipment.

A comparison of Tables 2, 3 and 4 with Appendix Tables A4, A5 and A6 shows that the number of observations (vintages) has increased in most industries when we incorporate more discard years. For instance, in transport equipment only rubber $\&$ plastic and machinery \& equipment have shown a decline in the number of observations when we use three years' discard information. This decline, however, is marginal, say by one observation. The same is also true for machinery, where there is only one industry which has shown a decline in the number of observations; this is transport equipment. The number of observation in this industry has declined from 54 to 47. However, the asset type computer has shown a decline in a large number of industries, though the magnitude of decline is quite small. In 10 industries the number of observations has declined on average by 3 observations, with the maximum being 8 in other non-metallic minerals, and the minimum being 1 in paper \& paper products, office machinery, computers, and TV \& radio manufacturing. In all other industries, for all three asset types, the number of observation has increased, on average by 4 observations in transport equipment, 2 in computers and 5 in machinery.

The estimated standard errors are small and the coefficients are significant at the 1 percent level. If the standard errors are very high and the confidence intervals are very wide, the non-linear results will not be useful. In all cases, the 95 percent confidence intervals are generally quite narrow for both $\alpha$ and $\lambda$; the differences between the upper and lower confidence intervals are quite small. The $\mathrm{R}^{2}$ values are generally high; however, as discussed in the non-linear regression literature, one should not over rely on the $\mathrm{R}^{2}$ statistic, but also look at the fitted lines. Hence, together with these statistics, we have also examined all the estimated regression lines along with the actual ones. Figure 2 provides the actual and estimated survival functions for three asset types in the food, tobacco \& beverages industry. It can be seen that the estimated lines fit very well to the actual data in almost all the asset types. However, this does not hold for all industries and asset types. Such cases, where the estimated line does not fit the actual data, are more common in single discard models. We observe that the incorporation of more discard years into the estimation improves the fitted curves in most cases (for example, see Appendix, Figure A2). However there are some cases which have a bad fit across both models, even when taking into account discards of three years. We have, however, reported the results for all these cases, even if the fitted lines have not shown a perfect approximation (they are highlighted while reporting the estimated lifetimes), as all other goodness of fit statistics have been satisfactory. Even if we 


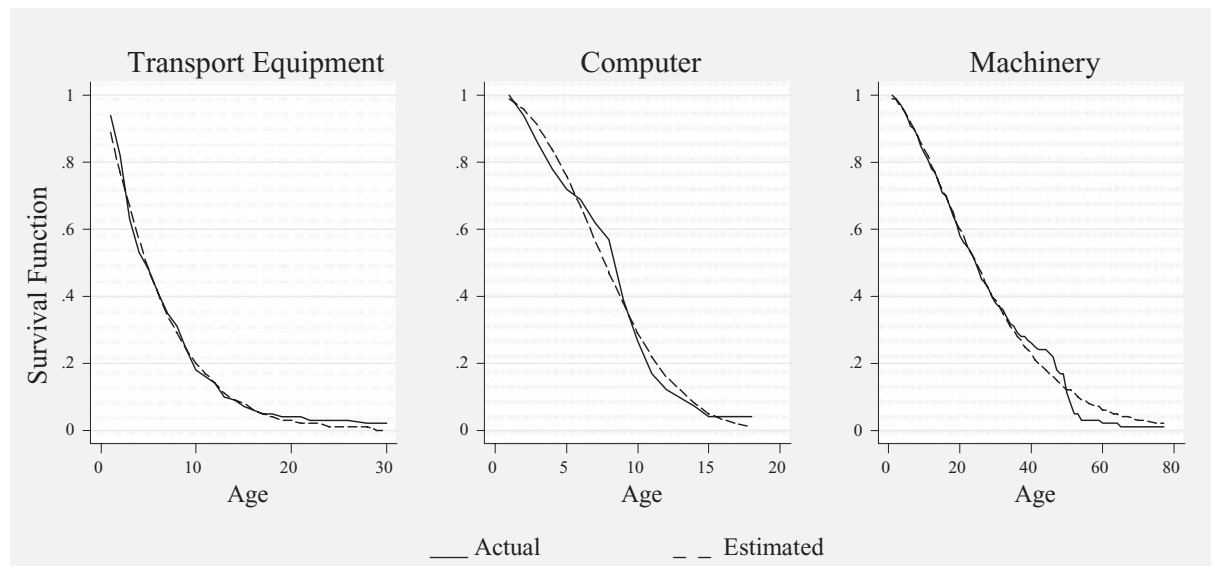

Figure 2. Actual vs. Estimated Survival Function, Food, Beverages \& Tobacco Industries

exclude these cases while calculating an average lifetime for the entire manufacturing sector, they vary only marginally.

\subsection{Estimated Lifetimes: Transport Equipment}

The estimated lifetimes for transport equipment are presented in Table 5. It can be discerned from the table that the transport equipment has shown an average service life of 8.3 years while we considered only one discard year. However, this has changed to 6.5 years when we take into account three years of discards. As mentioned earlier, we advocate the measures based on three years' discard data, as it includes more discard information. Moreover, it provides a better fit for the estimated regression lines compared to the one year case. Hence, the results produced by three years' discard may be considered more reliable. In four industries (basic chemicals, rubber \& plastic products, other non metallic mineral products, and electrical machinery) the estimated regression line had almost no good fit to actual data. The average lifetime across industries remains almost the same, even when we exclude these industries. The lifetime varies notably across industries, which nevertheless have narrowed down as we include more discard information. The industries publishing \& printing and office machinery, computers, radio, TV \& communication equipment have shown the lowest estimates of average lifetimes. Interestingly, as mentioned before, these are among the industries that have produced relatively high values for $\alpha$. The industries basic chemicals and petroleum, cokes \& nuclear fuel have shown the highest lifetime for transport equipment.

The resulting lifetime that hovers around 7 years, with a minimum of 3.8 years in publishing \& printing, may appear to be low for transport equipment. However, given our data, these results do not come as a surprise. The discard data makes a distinction between final destination of discards: whether they are scrapped, sold in the second-hand market, or returned back to the lease company. Second-hand sale and returning to lease company are more prominent in the asset type transport 
TABLE 5

Estimates of Expected Average Service Lifetimes: Transport EQUIPMENT

\begin{tabular}{lcc}
\hline \hline Industry & Single Discard & 3 Years Discard \\
\hline $15+16$ & 8.1 & 6.3 \\
$17-19$ & $4.9^{*}$ & 6.4 \\
$20+33+36$ & 6.1 & 5.4 \\
21 & 5.3 & 4.8 \\
22 & 4.1 & 3.8 \\
23 & $7.6^{*}$ & 9.0 \\
24 & $20.0^{*}$ & $12.0^{*}$ \\
25 & $8.5^{*}$ & $7.2^{*}$ \\
26 & $10.8^{*}$ & $4.7^{*}$ \\
27 & $7.4^{*}$ & 7.8 \\
28 & 7.5 & 5.0 \\
29 & 7.6 & 5.2 \\
$30+32$ & $2.9^{*}$ & 4.3 \\
31 & $4.6^{*}$ & $6.7^{*}$ \\
$34+35$ & $18.8^{*}$ & 8.3 \\
Average & $8.3(6.5)$ & $6.5(6.0)$ \\
\hline
\end{tabular}

Notes: Single Discard refers to the lifetimes estimated using only one year's discard information; 3 Years Discard refers to those estimated using 3 years' discard information.

*Indicates that the fitted curve is not close to the actual function; hence the results are less reliable. Figures in parentheses are averages excluding cases with less perfect fit.

equipment (see Appendix, Table A7). The share of total discard value in transport equipment going back to the leased company is as high as 56 percent in 2000. Also, 35 percent of total transport equipment was sold in the second-hand market, with almost 50 percent of industries registering a second-hand sale of more than 30 percent. Only 2.5 percent of transport equipment was fully scrapped. This suggests the strong presence of leased assets and a large second-hand market for the asset type transport equipment. In almost all the industries with lower lifetime estimates for transport equipment, we observe that the share of assets going back to the lease company and second-hand sale is more than 80 percent. The story is quite different in the case of computers and machinery. On average 53 percent of computers are fully scrapped, while 17 percent are sold on the second-hand market. Similarly, machinery shows almost 52 percent scrap, while 13 percent is sold in the secondhand market.

The average duration of a lease contract is probably shorter than the average age of owned transport equipment, which will therefore result a shorter lifetime estimate (Bergen et al., 2005). The larger share of second-hand sales indicates that this asset is sold for reuse and hence not used by the firm until the end of its actual service life, which will also reduce the lifetime estimate. Nevertheless, we make no adjustment for the presence of second-hand market and leased assets in our study. As we have mentioned before, discard in our analysis is defined to include any withdrawal of an asset from the production process. Since the discard of an asset implies that it is no more profitable to keep (or efficiently use) it in the production process in that particular industry, it is reasonable to expect that no competitive firm will be willing to use an asset discarded by another firm in the same industry, 
TABLE 6

Estimates of Expected Average Lifetimes: Computers

\begin{tabular}{lcc}
\hline \hline Industry & Single Discard & 3 Years Discard \\
\hline $15+16$ & 19.0 & 8.1 \\
$17-19$ & $26.7^{*}$ & $9.0^{*}$ \\
$20+33+36$ & $13.7^{*}$ & 6.9 \\
21 & $12.5^{*}$ & 6.9 \\
22 & 16.8 & 9.7 \\
23 & $16.3^{*}$ & 10.4 \\
24 & 28.1 & 8.7 \\
25 & $24.1^{*}$ & $9.1^{*}$ \\
26 & $23.7^{*}$ & 8.0 \\
27 & $17.4^{*}$ & 15.0 \\
28 & 9.0 & 7.6 \\
29 & 13.7 & 6.9 \\
$30+32$ & 6.8 & 7.8 \\
31 & $26.8^{*}$ & 8.9 \\
$34+35$ & 9.8 & 6.9 \\
Average & $17.6(15.9)$ & $8.7(8.6)$ \\
\hline
\end{tabular}

Notes: Single Discard refers to the lifetimes estimated using only one year's discard information; 3 Years Discard refers to those estimated using 3 years' discard information.

*Indicates that the fitted curve is not close to the actual function; hence the results are less reliable. Figures in parentheses are averages excluding cases with less perfect fit.

as it might adversely affect its efficiency and hence competitiveness. Similarly, with regard to return to the lease company, we assume that the economic life of that asset to this particular industry is over, and hence it is being discarded from that industry. Since most of the leased assets are found to be in transport assets, this assumption may be valid, as most discarded automobiles (or those sold in the second-hand market) are generally going to final consumers.

\subsection{Estimated Lifetimes: Computers}

The estimated lifetimes for computers are shown in Table 6. Here, one should keep in mind that the asset type computers includes not only personal computers, but also mainframe computers and computer associated equipment such as printers. Therefore, this is not an estimate of lifetime for computers per se, rather an average estimate for computers and related equipment. It is evident from the table that the single discard year approach has always tended to overestimate the lifetimes of computers. On average, in our preferred estimate of three year discard case, it shows a lifetime hovering around 9 years with the highest registered in the basic metals industry. There are two industries, textile \& leather products and rubber $\&$ plastic products, which have obtained a relatively bad fit for the estimated regression line. This number, however, has declined from 8 to 2 as we move from the single discard to the three year discard case. The average lifetime across all industries remains almost the same, even if we exclude these industries. The cross-industry variation has declined substantially as we incorporate more discard information. 
TABLE 7

Estimates of Expected Average Lifetimes: Machinery

\begin{tabular}{lcc}
\hline \hline Industry & Single Discard & 3 Years Discard \\
\hline $15+16$ & 31.2 & 27.9 \\
$17-19$ & 28.4 & 22.8 \\
$20+33+36$ & 34.7 & 24.9 \\
21 & $51.5^{*}$ & 22.5 \\
22 & 22.6 & 13.6 \\
23 & $59.8^{*}$ & $36.0^{*}$ \\
24 & 30.0 & 24.7 \\
25 & 34.7 & 29.5 \\
26 & 35.8 & 28.7 \\
27 & $52.8^{*}$ & 33.0 \\
28 & 28.5 & 29.2 \\
29 & 24.5 & 19.6 \\
$30+32$ & 13.6 & 16.7 \\
31 & $28.8^{*}$ & 41.0 \\
$34+35$ & 39.9 & 23.7 \\
Average & $34.5(29.4)$ & $26.2(25.5)$ \\
\hline
\end{tabular}

Notes: Single Discard refers to the lifetimes estimated using only one year's discard information; 3 Years Discard refers to those estimated using 3 years' discard information.

*Indicates that the fitted curve is not close to the actual function; hence the results are less reliable. Figures in parentheses are averages excluding cases with less perfect fit.

\subsection{Estimated Lifetimes: Machinery}

For the asset type machinery, on average the estimated lifetime varies from 26 to 34 years, for the two alternative survival functions (Table 7). As seen before, in most industries the single discard year estimates tend to produce marginally higher lifetimes compared to the three discard year estimates. Also the cross-industry variation has declined significantly as we incorporate more discard information. The industries publishing \& printing, office machinery, radio \& TV manufacturing, and machinery \& equipment have shown the lowest lifetimes. The highest lifetime in the three year discard model is registered in the industries electrical machinery, petroleum, cokes \& nuclear fuel, and basic metals. However, for the industry petroleum products we did not find a good fit for the estimated model. If we exclude this industry while taking the average for the entire sector, the lifetime decreases marginally in the preferred estimates of three year average case. The lower rates observed for the industry office machinery, radio \& television manufacturing is rather appealing as one would expect the service life in such a highly dynamic industry, which is subject to considerable technological advancement, to have a relatively higher scrapping rate compared to high sunk cost industries such as petroleum refinery and basic metals.

\subsection{Lifetime Estimates: A Comparative Perspective}

In Table 8 we compare our estimates of lifetimes for different two-digit industries with two earlier studies conducted for the Dutch manufacturing industry, i.e. Bergen et al. (2005) and Meinen (1998). While the former study used a somewhat 
TABLE 8

Comparison of Asset Lifetime Estimates With Earlier Studies (industry wise)

\begin{tabular}{|c|c|c|c|c|c|c|c|c|c|c|}
\hline \multirow[b]{2}{*}{ Industry } & \multirow{2}{*}{$\frac{\text { Canada }}{\mathrm{M}}$} & \multirow{2}{*}{$\begin{array}{c}\text { U.S. } \\
(\mathrm{BLS}) \\
\mathrm{M}\end{array}$} & \multicolumn{3}{|c|}{$\begin{array}{l}\text { Netherlands } \\
\text { (Bergen } \text { et al.) }\end{array}$} & \multicolumn{2}{|c|}{$\begin{array}{l}\text { Netherlands } \\
\text { (Meinen) }\end{array}$} & \multicolumn{3}{|c|}{$\begin{array}{c}\text { Netherlands } \\
\text { (New Estimates) }\end{array}$} \\
\hline & & & M & $\mathrm{T}$ & $\mathrm{C}$ & M & $\mathrm{C}$ & M & $\mathrm{T}$ & $\mathrm{C}$ \\
\hline Food, beverages \& tobacco ${ }^{1}$ & 11 & 24 & 27 & 6 & 12 & 43 & 13 & 28 & 6 & 8 \\
\hline Textile \& leather products ${ }^{2}$ & 10 & 18 & 35 & 5 & 14 & 28 & 15 & 23 & 6 & 9 \\
\hline $\begin{array}{l}\text { Wood \& wood products, } \\
\text { medical \& optical equipment } \\
\text { \& other manufacturing }{ }^{3}\end{array}$ & 11 & 17 & $25^{*}$ & $6^{*}$ & $8^{*}$ & & & 25 & 5 & 7 \\
\hline Paper \& paper products & 18 & 19 & $27^{*}$ & 5 & 6 & 27 & 10 & 22 & 5 & 7 \\
\hline Publishing \& printing & & 18 & 35 & 5 & 8 & & & 14 & 4 & 10 \\
\hline $\begin{array}{l}\text { Petroleum products; cokes \& } \\
\text { nuclear fuel }\end{array}$ & 16 & 25 & 22 & 5 & 8 & 34 & 10 & $36^{*}$ & 9 & 10 \\
\hline $\begin{array}{l}\text { Basic chemicals \& man-made } \\
\text { fibers }\end{array}$ & 13 & 19 & 30 & 7 & 12 & 38 & 13 & 25 & $12 *$ & 9 \\
\hline Rubber \& plastic products ${ }^{4}$ & 12 & 16 & $30 *$ & $5^{*}$ & $12 *$ & & & 29 & $7 *$ & 9 \\
\hline $\begin{array}{l}\text { Other non-metallic mineral } \\
\text { products }^{5}\end{array}$ & 13 & 22 & 30 & $5^{*}$ & $8^{*}$ & & & 29 & $5^{*}$ & 8 \\
\hline Basic metals $^{6}$ & & 31 & $33^{*}$ & 7 & $8 *$ & 36 & 16 & 33 & 8 & 15 \\
\hline Fabricated metal products & 10 & 28 & 33 & 5 & 8 & & & 29 & 5 & 8 \\
\hline Machinery \& equipment n.e.c. ${ }^{7}$ & 8 & 29 & $33^{*}$ & 5 & 12 & & & 20 & 5 & 7 \\
\hline $\begin{array}{l}\text { Office machinery \& computers, } \\
\text { radio, TV \& communication } \\
\text { equipment }^{8}\end{array}$ & 8 & & 20 & $5 *$ & $6^{*}$ & & & 17 & 4 & 8 \\
\hline Electrical machinery n.e.c. ${ }^{9}$ & & 16 & $18^{*}$ & $5^{*}$ & $6^{*}$ & & & 41 & $7 *$ & 9 \\
\hline Transport equipment ${ }^{10}$ & 9 & 18 & 30 & $5^{*}$ & 5 & & & 24 & 8 & 7 \\
\hline
\end{tabular}

Notes: $\mathrm{M}$ denotes machinery, $\mathrm{T}$ denotes transport equipment and $\mathrm{C}$ denotes computers.

The figures for Canada are taken from OECD capital manual, and the figures for the U.S. are the revised estimates available at the Bureau of Labor Statistics website, http://www.bls.gov/mfp/ mprcaptl.htm. For the U.S. the estimates for machinery are simple averages across three asset types, e.g. metal working machinery, special industry machinery, n.e.c., and general industrial equipment including materials handling. For Canada and the U.S., no estimates for computers and transport are available. Similarly, for the Netherlands (in Meinen), industry-wise estimates for transport equipment are not available.

In Bergen et al., values with a * sign are lifetimes which are taken from other industry estimates or derived based on expert guess, due to bad estimates for these industries/assets (see Bergen et al.), and in the new estimates they are the cases where we obtain no perfect fit in the estimated regression model.

In some cases the industry estimates are averages across several industry groups. They are: (1) for Canada, the average for food \& beverages and tobacco, and for the U.S., the average for food \& kindred products and tobacco; (2) for Canada, the average for leather and textiles, for the Netherlands (in Meinen), only textiles and for the U.S., the average for textile \& mill products, apparel \& other textiles products and leather \& leather products; (3) for Canada, the average for wood and other manufacturing industries, for the Netherlands (in Bergen et al.), average for wood, medical \& optical equipment and other manufacturing and for the U.S., the average for lumber \& wood products, furniture \& fixtures, instruments \& related products and miscellaneous manufacturing; (4) for Canada, the average for rubber \& plastic products; (5) for the U.S., stone, clay \& glass products; (6) for the Netherlands (in Meinen), basic metal and fabricated products together; (7) for Canada, machinery industries, and for the U.S., industrial machinery and equipment; (8) for Canada, electrical and electronic products, for the Netherlands (in Bergen et al.) average for office machinery \& computers and radio, TV etc; (9) for the U.S., electronic and other electrical equipment; and (10) for the Netherlands (in Bergen et al.), the average for cars \& trailers and other transport equipment and for the U.S., the average for motor vehicles \& equipment and other transport equipment. 
similar methodology ${ }^{21}$ to ours (but with one year of discard data), the latter used a hazard function to estimate lifetimes. The table also contains estimates for the United States and Canada for corresponding two-digit industries, but only for machinery. Industry-wise estimates for the U.S. and Canada were not available for transport equipment and computers. Similarly, for the Netherlands, in Meinen, no industry-wise estimates were available for transport equipment. Hence an elaborated comparison was possible only for the machinery asset. Similarly, lifetime estimates available for some industries in Bergen et al. are not based on actual information on capital stock and discard. Rather they are estimates taken from other industries or derived based on expert guesses, as they could not obtain robust results for these industries (such cases are asterisked in Table 8). Hence, a strict comparison is meaningful only for industries for which robust estimates are available.

A comparison of our results with the previous estimates for the Netherlands shows that our estimates are generally slightly higher than Bergen et al. ${ }^{22}$ for transport equipment, with a few exceptions. For machinery, our estimates lie in between Bergen et al. and Meinen in 2 out of 6 industries for which estimates are available in these two studies. In computers, our estimates are higher than Bergen et al. in 7 industries, lower in 6 industries and the same in 2 industries. However, in 4 out of 8 industries where our estimates are higher, the estimates provided by

\footnotetext{
${ }^{21}$ One basic difference between the present study and Bergen et al. (2005), as mentioned before, is that we feed more discard information into the estimation of lifetimes. It should also be noted that there are other differences between the two in the way the data have been used. For instance, we have excluded all those firms that have not reported zero or positive discard in at least one vintage (i.e. those firms with missing observations throughout all the vintages in the data) from the sample. Bergen et al., however have included all such firms assuming zero discards under the presumption that these are not real missing cases. Unfortunately, there is no way to verify the validity of this underlying assumption. The problem is that if this assumption is not true, i.e. if it is a real missing case, its inclusion will overestimate capital stock (underestimate discards). Hence we opt to exclude such firms both from capital stock and discard data. Further, we exclude all those cases where the discard values are higher than capital stock, as it is an impossible situation. However, they have corrected the data in these cases by attributing such discard cases to a nearby vintage year. But, there is no criterion on which one can decide to which vintage it can be attributed to, other than arbitrary selection. In any case, this is not a severe problem, as the number of such cases is quite negligible in all the three asset types we have considered. The treatment of discard has also been different, at least in asset type machinery, where they do not consider second-hand sales and return to lease company (the share of latter is quite marginal though) as discards, while we do. And in transport equipment, they have raised the lifetime estimate for all industries, using a factor which they have calculated for transport equipment in food products, beverages and tobacco industries by excluding leased assets from the sample. In our regression analysis we allow only three exaggerated tails, while they have included up to five. Finally they have used two benchmarks in most cases, and selected the results that appear to be reasonable. Since our methodology incorporates three years' discard information, it was not possible for us to consider the second benchmarks due to lack of adequate data to include more discard information. The observed differences in Table 8 can also be due to the differences in methodology in that our results carries three years' discard information.

${ }^{22}$ It may, however, be noted that in order to deal with the problem of leased assets, Bergen et al. (2005) have raised their estimates for transport equipment by a factor of 0.712 years, which they have obtained from the relationship between lifetimes estimated, including and excluding leased asset types for food and tobacco manufacturing. Such an analysis was possible only for food and tobacco manufacturing, as the information on return to lease company is only available since 1999, and the only industry for which there is a meaningful amount of data after 1999 is food and tobacco. We did not, however, opt to make such an adjustment because the share of leased asset varies significantly across industries (see Appendix, Table A7), and it may not be appropriate to use a common factor across industries. We also observed that if the leased transport equipment is excluded from the analysis, the lifetime for food and tobacco manufacturing increases by almost 1.3 years.
} 
Bergen et al. are estimates borrowed from other industries or guesstimates. And our estimates are always lower than Meinen's estimates for computers, by about 1-5 years. In general, for machinery and computers, our estimates are relatively lower than the estimates of Meinen. The differences between our estimates and Meinen's estimates are on average 7 (3) years for machinery (computers), while the new estimates differ from Bergen et al.'s estimate on average by $7(3,1)$ years for machinery (computer, transport equipment). These differences, however, vary across industries. The observed differences are substantial in some cases, while trivial in others.

We also compare our estimates with estimates available for the United States and Canada for machinery. This comparison, however, is tentative in nature, because they are calculated using different methodology/assumptions. For the U.S., the estimates are taken from the Bureau of Labor Statistics (2006), ${ }^{23}$ where they are provided for three asset types: metal working machinery, special industry machinery n.e.c., and general industrial equipment including materials handling. We have considered an average of these three asset types for different industries, as the estimate for machinery. Similarly for Canada, the figures, which are available for different industries, are taken from the OECD capital manual. However, in the latter case we have no information about the components of machinery (more importantly whether transport equipment is included or not). This is important because a comparison is meaningful only if the same cohorts of assets are included in all the estimates. Nevertheless, we do compare them as we do not have a better estimate to compare them with. Interestingly the Canadian estimates are smaller than both the U.S. and all the earlier and current estimates for the Netherlands in all industries. This is surprising. For instance, the U.S. and Canada share not only geographical proximity, but also many economic characteristics, which makes it less probable to have such huge differences in their asset lives. Hence, it may be an indication of differences in asset composition. Of course, one could argue that the discard decision and consequently the lifetimes of assets depends on many factors including tax policy, innovation, output growth and input prices, among others, which can vary across countries, leading to differences in lifetimes. This is an issue that warrants further research. However, even if one allows for such issues, one would not expect to have such huge lifetime differences, especially between countries of similar economic conditions. When the U.S. figures are compared with the Dutch estimates, it is seen that machinery in the Netherlands is more than in the U.S. in almost all industries, except in publishing \& printing and machinery $\&$ equipment, where it is less by 4 and 9 years, respectively. The difference between the estimates is 6 years on average, with the largest difference being in electrical machinery. These differences may be real, or a reflection of the asset composition.

The average lifetimes for total manufacturing, calculated using the new estimates, are presented in Table 9 along with similar figures available from earlier

\footnotetext{
${ }^{23}$ The data was downloaded from the BLS website (http://www.bls.gov/mfp/mprcaptl.htm) on June 6, 2006.
} 
TABLE 9

Comparison of Asset Lifetime Estimates with Earlier Studies (total manufacturing)

\begin{tabular}{lccc}
\hline \hline & Transport & Machinery & Computers \\
\hline Canada (OECD)* & NA & 12 & NA \\
Canada (Baldwin et al.)**\# & $11(7)$ & $14(12)$ & $10(9)$ \\
U.S. (BLS)* & 10 & 21 & 6 \\
U.S. (BEA)** & 9 & 18 & 7 \\
Japan (Nomura)** & 14 & 13 & 7 \\
Netherlands (Meinen)*** & 10 & 35 & 12 \\
Netherlands (Bergen et al.)* & 5 & 29 & 9 \\
Netherlands (New Estimates) $^{*}$ & 6 & 26 & 9
\end{tabular}

Notes:

* Simple average across various industries.

**Simple average across various asset types.

***Estimate for total manufacturing.

NA, not available.

\#Figures in parentheses are ex ante estimates.

The U.S. estimates for computers from BEA (Bureau of Economic Analysis, 2003) are for office and computing equipment and from the BLS are the average across mainframe computers, personal computers, storage devices, printers, terminals, tape drivers and other office and computing equipment. It is not clear whether it is an estimate for the manufacturing sector alone. Also the U.S. estimates for transport equipment are for trucks, buses and trailers, excluding those used in passenger services and other service industries.

studies within and outside the Netherlands. Our results for transport equipment are close to the ex ante estimates provided in Baldwin et al. for Canada, while they are considerably lower than Nomura's estimates for Japan. ${ }^{24}$ Also the new estimates lie between the two previous estimates available for the Netherlands. The new estimates for machinery, when compared with earlier estimates for the Netherlands, are lower than two previous estimates, though relatively closer to the estimates by Bergen et al., and considerably lower than Meinen. Nevertheless they are still larger than the Japanese and the Canadian estimates, though relatively closer to the Bureau of Labor Statistics estimates for the U.S. This is also true for two earlier studies for the Netherlands. As mentioned earlier, these differences could be due either to the differences in asset composition, or to the differences in the factors that determine the scrapping behavior of firms. For computers, our estimates are the same as Canadian estimates, but higher than U.S. and Japanese estimates. They are also the same as Bergen et al.'s estimates for the Netherlands but lower than Meinen's estimates. The U.S. estimates for computers are lower than our estimates, but it is not clear whether these are estimates only for manufacturing. This is very important as it is also possible that the share of personal computers, which are subject to more rapid technological obsolescence, is lower in manufacturing industries compared to service sectors. In the manufacturing sector, computer equipment may largely consist of mainframe computers or highly customized numerically controlled machines, which may not be replaced as quickly as personal computers.

\footnotetext{
${ }^{24}$ Both Baldwin et al. and Nomura have employed a survival analysis to derive lifetimes.
} 


\section{CONCLUSION}

In this paper we present estimates of average service life for three different asset types - transport equipment, computers, and machinery-for the manufacturing industries in the Netherlands. For this purpose, we exploit a unique firm level dataset on directly observed capital stock and discard of these asset types. A Weibull distribution function is estimated using a non-linear regression estimation procedure, where the survival function of a select asset is regressed on its age. The Weibull parameters are then used to calculate the expected service life of the assets. In the measurement of lifetimes, unlike earlier studies, we have incorporated more information on discard behavior of each vintage and hence better approximation of survival rates at each age.

The estimated regression coefficients are found to have a good fit in general; this is further improved when we incorporate more discard information into the estimation. Moreover, the number of observations has increased in most industries when more discard years are added into the model. On average, transport equipment has shown a lifetime of 6 years, while machinery and computers have shown 26 and 9 years, respectively. While our estimates for transport equipment are quite close to estimates for Canada, they are significantly lower than that for Japan. A comparison of our estimates with that of earlier estimates for the Netherlands indicates that they lie in between the estimates provided by two previous studies. The asset transport equipment seems to have a lower lifetime in our estimate, at least in some industries, which may be attributed to the large share of leased assets and second-hand sales in the transport equipment component, with possibly lower lengths of lease contracts. This point, however, needs further substantiation, looking at the share of these factors in other countries, such as Japan for instance. For machinery, our estimates are different from both Japan and Canada, but closer to the previous estimates for the Netherlands and to some extent closer to the U.S. These differences could be due to either compositional differences or differences in determinants of scrapping across countries. In the latter case, further research is warranted to unearth the determinants of scrapping behavior of firms. Computers, however, have produced a lifetime that is almost the same as Canadian estimates, but slightly higher than the U.S. and Japanese estimates.

It may be noted that there is wide variation in asset lifetimes across industries. The cross-industry variation is seen to be decreasing as we incorporate more discard information. However it still exists. The difference is observed despite the fact that we have considered a relatively high level aggregation, where one might expect to have similar estimates. Nevertheless, apart from the technological specificities, which may be countered by the high level aggregation we have used, we have no explanation for this. The observed difference may either be a reality, or indicate noise. It is a worthwhile topic for future research. Similarly, since there are observed differences across different countries in terms of their lifetimes, especially in machinery, if it is a reality, it is also important to examine the determinants of scrapping by firms. This is particularly important from the perspective of the relationship between innovation and investment/discard behavior, particularly in view of increasing technological obsolescence. 


\section{APPENDIX: THE DATA}

As mentioned in the text, the data used in this study are taken from two distinct surveys conducted by Statistics Netherlands (CBS) - the capital stock survey and the discard survey. The capital stock data were collected between 1993 and 2003 for manufacturing firms coming under the ISIC two-digit level. Each year one or more two-digit industries have been surveyed, and the same industry will be subjected to a second survey after five years. The information on existing capital stock, with vintage structure, is available for eight asset types:

1 Land and sites (only purchase and sale of sites)

2 Industrial buildings (offices, shops, etc)

3 Civil engineering works (including site improvements: roads, pipelines, etc)

4 External transport equipment (excavators, drudging machines, etc)

5 Internal means of transport (cranes, pulleys, etc)

6 Computers and associated equipment (computers, printers, etc)

7 Machinery and equipment

8 Other tangible fixed assets (furniture, freight containers, etc).

In the present analysis, we consider only asset types 4-7. We have further merged internal means of transport (5) with machinery and equipment (7), as the capital stock survey provides information on these assets together, though the discard survey provides them separately.

As mentioned in the paper, the capital stock in year $t-1$ is merged for each vintage to the discard in years $t, t+1$ and $t+2$. Prior to merging the two databases, we have deleted all firms reported more than once (for same asset, vintage and ownership type causing double counting and hence an exaggeration of actual data), i.e. firms with double reporting in both surveys. Tables A1 and A2 show the number of firms reported to various surveys on capital stock and discard respectively. It can be seen that the number of manufacturing firms reported to the capital stock survey is 1354 in the first round and 1108 in the second round. The number of firms varies from 10 (7) in the petroleum, coke \& nuclear fuel industry to 247 (234) in the food processing industry in the first (second) round. As is evident from Table A2, the number of manufacturing firms reported to various discard surveys during 1993-2001 varies over the years, the highest response rate being in 1997 and the lowest in 1996. As was observed in the capital stock survey, the largest number of firms reported is found to be in the food processing industry throughout the period, while the lowest number is observed in the petroleum, coke $\&$ nuclear fuel industry. Note that all the firms reported in these tables are not considered in our final sample, as we had to apply a number of cleansing rules to clean up the data, which resulted in elimination of a number of firms from the sample (see text). 
TABLE A1

Number of Firms Reported to Two Benchmark Capital Stock Surveys

\begin{tabular}{|c|c|c|c|c|}
\hline \multirow[b]{2}{*}{ Industry } & \multicolumn{2}{|c|}{ First Round } & \multicolumn{2}{|c|}{ Second Round } \\
\hline & Survey Year & No. of Firms & Survey Year & No. of Firms \\
\hline $15+16$ & 1993 & 247 & 1998 & 234 \\
\hline $17-19$ & 1994 & 73 & 1999 & 54 \\
\hline $20+33+36$ & 1994 & 83 & 1999 & 94 \\
\hline 21 & 1995 & 68 & 2000 & 77 \\
\hline 22 & 1997 & 107 & NA & NA \\
\hline 23 & 1994 & 10 & 1999 & 7 \\
\hline 24 & 1997 & 144 & NA & NA \\
\hline 25 & 1996 & 68 & 2001 & 77 \\
\hline 26 & 1996 & 66 & 2001 & 67 \\
\hline 27 & 1994 & 40 & 1999 & 37 \\
\hline 28 & 1995 & 151 & 2000 & 153 \\
\hline 29 & 1996 & 167 & 2001 & 172 \\
\hline $30+32$ & 1994 & 21 & 1999 & 21 \\
\hline 31 & 1994 & 36 & 1999 & 37 \\
\hline $34+35$ & 1995 & 73 & 2000 & 78 \\
\hline Total & & 1,354 & & \\
\hline Total* & & 1,103 & & 1,108 \\
\hline
\end{tabular}

Notes:

*Excludes industries 22 and 24 for which the second round is not available. NA, not available.

TABLE A2

Number of Firms Reported to Various Discard Surveys

\begin{tabular}{lrrrrrrrr}
\hline \hline Industry & 1994 & 1995 & 1996 & 1997 & 1998 & 1999 & 2000 & 2001 \\
\hline $15+16$ & 199 & 208 & 190 & 229 & 234 & 189 & 191 & 179 \\
$17-19$ & 59 & 48 & 42 & 50 & 49 & 52 & 41 & 34 \\
$20+33+36$ & 81 & 67 & 66 & 81 & 86 & 93 & 91 & 86 \\
21 & 55 & 66 & 55 & 62 & 73 & 62 & 77 & 69 \\
22 & 111 & 100 & 90 & 103 & 100 & 87 & 84 & 85 \\
23 & 10 & 10 & 10 & 10 & 10 & 7 & 8 & 6 \\
24 & 116 & 106 & 108 & 140 & 132 & 127 & 134 & 121 \\
25 & 59 & 60 & 61 & 69 & 63 & 62 & 62 & 77 \\
26 & 44 & 50 & 62 & 70 & 66 & 59 & 59 & 65 \\
27 & 38 & 33 & 30 & 34 & 32 & 36 & 32 & 31 \\
28 & 113 & 133 & 97 & 137 & 133 & 123 & 155 & 116 \\
29 & 142 & 128 & 163 & 147 & 147 & 130 & 138 & 172 \\
$30+32$ & 19 & 14 & 10 & 15 & 16 & 21 & 18 & 22 \\
31 & 36 & 28 & 29 & 33 & 34 & 36 & 35 & 31 \\
$34+35$ & 51 & 64 & 54 & 65 & 69 & 61 & 79 & 57 \\
Total & 1,133 & 1,115 & 1,067 & 1,245 & 1,244 & 1,145 & 1,204 & 1,151 \\
\hline
\end{tabular}

Notes: In the last two years data is also available on industries 11, 14 and 40; nevertheless, they are not included here. If they are included, the number of firms in 2000 increases to 1281 and in 2001 to 1211.

Furthermore, the table contains only manufacturing industries which are considered in the present study. The data are available for other industries such as crude petroleum and natural gas production (11), other mining and quarrying (14), electricity, gas and water supply (40), collection, purification and distribution of water (41), and other business activities, such as legal and economic activities, 
architectural and engineering activities, advertising, activities of employment agencies and other business activities (74). The number of firms increases to 1379 (1128) and 1150 (1127) respectively in the first and second rounds, if we include these industries; the figures in parentheses indicate that the same industries are considered in both, while others include different industries in each round, for example 22 and 24 in the first round and 40, 41 and 74 in the second round.

TABLE A3

Share of Second-Hand Investment in Total Investment (\%)

\begin{tabular}{lccc}
\hline \hline Industry & Transport Equipment & Computer & Machinery \\
\hline $15+16$ & 3.0 & 0.1 & 0.5 \\
$17-19$ & 1.5 & 0.0 & 0.2 \\
$20+33+36$ & 2.5 & 0.4 & 2.8 \\
21 & 2.6 & 0.0 & 0.3 \\
22 & 0.6 & 0.2 & 1.8 \\
23 & 0.2 & 0.0 & 0.0 \\
24 & 0.3 & 0.3 & 0.1 \\
25 & 1.1 & 0.3 & 4.2 \\
26 & 0.7 & 3.9 & 0.3 \\
27 & 0.9 & 0.0 & 0.0 \\
28 & 1.0 & 0.0 & 0.0 \\
29 & 1.9 & 0.2 & 0.7 \\
$30+32$ & 0.0 & 0.0 & 0.0 \\
31 & 4.0 & 0.0 & 0.0 \\
$34+35$ & 2.6 & 0.0 & 0.0 \\
Total & 1.5 & 0.3 & 0.4 \\
\hline
\end{tabular}

Source: Investment survey, 2000, Statistics Netherlands.

TABLE A4

Estimated Regression Coefficients: Transport Equipment (Single Year Discard)

\begin{tabular}{lcccccccccr}
\hline \hline Industry & $\alpha$ & SE & LC & UC & $\lambda$ & SE & LC & UC & R $^{2}$ & DF \\
\hline $15+16$ & 1.169 & 0.031 & 1.105 & 1.233 & 0.117 & 0.002 & 0.113 & 0.120 & 0.994 & 23 \\
$17-19$ & 1.125 & 0.095 & 0.922 & 1.329 & 0.197 & 0.009 & 0.176 & 0.217 & 0.963 & 14 \\
$20+33+36$ & 1.000 & 0.132 & 0.715 & 1.285 & 0.165 & 0.012 & 0.138 & 0.192 & 0.899 & 14 \\
21 & 1.082 & 0.077 & 0.912 & 1.252 & 0.184 & 0.007 & 0.168 & 0.200 & 0.977 & 13 \\
22 & 1.821 & 0.181 & 1.439 & 2.203 & 0.218 & 0.008 & 0.200 & 0.235 & 0.971 & 17 \\
23 & 1.309 & 0.094 & 1.113 & 1.504 & 0.121 & 0.004 & 0.112 & 0.130 & 0.965 & 23 \\
24 & 1.000 & 0.174 & 0.634 & 1.366 & 0.050 & 0.006 & 0.038 & 0.062 & 0.535 & 19 \\
25 & 1.000 & 0.119 & 0.746 & 1.254 & 0.118 & 0.008 & 0.101 & 0.135 & 0.887 & 17 \\
26 & 1.000 & 0.104 & 0.779 & 1.221 & 0.093 & 0.005 & 0.082 & 0.103 & 0.900 & 18 \\
27 & 2.544 & 0.172 & 2.179 & 2.910 & 0.121 & 0.002 & 0.116 & 0.125 & 0.988 & 15 \\
28 & 1.211 & 0.063 & 1.075 & 1.346 & 0.125 & 0.003 & 0.119 & 0.132 & 0.984 & 16 \\
29 & 1.000 & 0.100 & 0.784 & 1.216 & 0.132 & 0.007 & 0.117 & 0.147 & 0.937 & 15 \\
$30+32$ & 2.919 & 0.282 & 2.324 & 3.514 & 0.310 & 0.007 & 0.294 & 0.325 & 0.985 & 12 \\
31 & 1.201 & 0.094 & 0.989 & 1.414 & 0.204 & 0.008 & 0.186 & 0.223 & 0.976 & 9 \\
$34+35$ & 1.000 & 0.146 & 0.682 & 1.318 & 0.053 & 0.006 & 0.040 & 0.066 & 0.800 & 14
\end{tabular}

Notes: SE is the standard error of the estimate. LC and UC are respectively the lower and upper $95 \%$ confidence intervals and DF is the degrees of freedom. 
TABLE A5

Estimated Regression Coefficients: Computers (Single Year Discard)

\begin{tabular}{|c|c|c|c|c|c|c|c|c|c|c|}
\hline Industry & $\alpha$ & SE & $\mathrm{LC}$ & $\mathrm{UC}$ & $\lambda$ & SE & $\mathrm{LC}$ & $\mathrm{UC}$ & $\mathrm{R}^{2}$ & DF \\
\hline $15+16$ & 1.416 & 0.087 & 1.230 & 1.603 & 0.048 & 0.002 & 0.044 & 0.052 & 0.977 & 17 \\
\hline $17-19$ & 1.071 & 0.160 & 0.713 & 1.428 & 0.036 & 0.007 & 0.022 & 0.051 & 0.910 & 12 \\
\hline $20+33+36$ & 1.926 & 0.186 & 1.529 & 2.322 & 0.065 & 0.002 & 0.060 & 0.070 & 0.953 & 16 \\
\hline 21 & 1.914 & 0.268 & 1.331 & 2.498 & 0.071 & 0.004 & 0.062 & 0.080 & 0.910 & 14 \\
\hline 22 & 1.000 & 0.079 & 0.830 & 1.170 & 0.060 & 0.003 & 0.053 & 0.066 & 0.954 & 16 \\
\hline 23 & 1.889 & 0.368 & 1.100 & 2.678 & 0.054 & 0.005 & 0.044 & 0.065 & 0.766 & 16 \\
\hline 24 & 1.055 & 0.049 & 0.952 & 1.159 & 0.035 & 0.002 & 0.032 & 0.038 & 0.983 & 18 \\
\hline 25 & 1.798 & 0.190 & 1.380 & 2.216 & 0.037 & 0.004 & 0.029 & 0.045 & 0.957 & 13 \\
\hline 26 & 1.415 & 0.090 & 1.221 & 1.609 & 0.038 & 0.002 & 0.034 & 0.043 & 0.979 & 15 \\
\hline 27 & 3.724 & 0.244 & 3.215 & 4.233 & 0.052 & 0.001 & 0.050 & 0.053 & 0.977 & 22 \\
\hline 28 & 2.073 & 0.082 & 1.900 & 2.246 & 0.099 & 0.001 & 0.096 & 0.101 & 0.994 & 18 \\
\hline 29 & 1.757 & 0.122 & 1.494 & 2.019 & 0.065 & 0.002 & 0.061 & 0.069 & 0.974 & 16 \\
\hline $30+32$ & 1.492 & 0.064 & 1.357 & 1.628 & 0.133 & 0.003 & 0.128 & 0.139 & 0.991 & 19 \\
\hline 31 & 1.207 & 0.158 & 0.855 & 1.559 & 0.035 & 0.006 & 0.023 & 0.047 & 0.933 & 12 \\
\hline $34+35$ & 2.747 & 0.210 & 2.293 & 3.200 & 0.091 & 0.002 & 0.087 & 0.094 & 0.980 & 15 \\
\hline
\end{tabular}

Notes: SE is the standard error of the estimate. LC and UC are respectively the lower and upper $95 \%$ confidence intervals and DF is the degrees of freedom.

TABLE A6

Estimated Regression Coefficients: Machinery (Single Year Discard)

\begin{tabular}{lcccccccccc}
\hline \hline Industry & $\alpha$ & $\mathrm{SE}$ & $\mathrm{LC}$ & $\mathrm{UC}$ & $\lambda$ & $\mathrm{SE}$ & $\mathrm{LC}$ & $\mathrm{UC}$ & $\mathrm{R}^{2}$ & $\mathrm{DF}$ \\
\hline $15+16$ & 1.234 & 0.024 & 1.186 & 1.282 & 0.030 & 0.000 & 0.029 & 0.030 & 0.992 & 52 \\
17 to 19 & 1.690 & 0.048 & 1.593 & 1.786 & 0.031 & 0.000 & 0.031 & 0.032 & 0.989 & 44 \\
$20+33+36$ & 1.000 & 0.041 & 0.917 & 1.083 & 0.029 & 0.001 & 0.028 & 0.030 & 0.961 & 47 \\
21 & 1.000 & 0.092 & 0.814 & 1.186 & 0.019 & 0.001 & 0.016 & 0.022 & 0.680 & 39 \\
22 & 1.316 & 0.067 & 1.179 & 1.453 & 0.041 & 0.001 & 0.039 & 0.043 & 0.970 & 29 \\
23 & 2.354 & 0.066 & 2.222 & 2.485 & 0.015 & 0.000 & 0.014 & 0.015 & 0.984 & 50 \\
24 & 2.130 & 0.076 & 1.977 & 2.283 & 0.030 & 0.000 & 0.029 & 0.030 & 0.982 & 48 \\
25 & 1.331 & 0.026 & 1.279 & 1.382 & 0.026 & 0.000 & 0.026 & 0.027 & 0.993 & 43 \\
26 & 1.252 & 0.076 & 1.099 & 1.405 & 0.026 & 0.001 & 0.025 & 0.028 & 0.934 & 46 \\
27 & 1.554 & 0.082 & 1.389 & 1.720 & 0.017 & 0.001 & 0.016 & 0.018 & 0.944 & 50 \\
28 & 1.574 & 0.060 & 1.454 & 1.693 & 0.032 & 0.000 & 0.031 & 0.032 & 0.973 & 62 \\
29 & 1.046 & 0.040 & 0.965 & 1.127 & 0.040 & 0.001 & 0.039 & 0.042 & 0.969 & 47 \\
$30+32$ & 1.494 & 0.023 & 1.447 & 1.540 & 0.066 & 0.000 & 0.065 & 0.067 & 0.997 & 59 \\
31 & 1.701 & 0.106 & 1.487 & 1.915 & 0.031 & 0.001 & 0.030 & 0.032 & 0.941 & 53 \\
$34+35$ & 1.425 & 0.094 & 1.237 & 1.614 & 0.023 & 0.001 & 0.021 & 0.024 & 0.909 & 54 \\
\hline
\end{tabular}

Notes: SE is the standard error of the estimate. LC and UC are respectively the lower and upper $95 \%$ confidence intervals and DF is the degrees of freedom.

(C) 2008 The Author

Journal compilation (C) International Association for Research in Income and Wealth 2008 


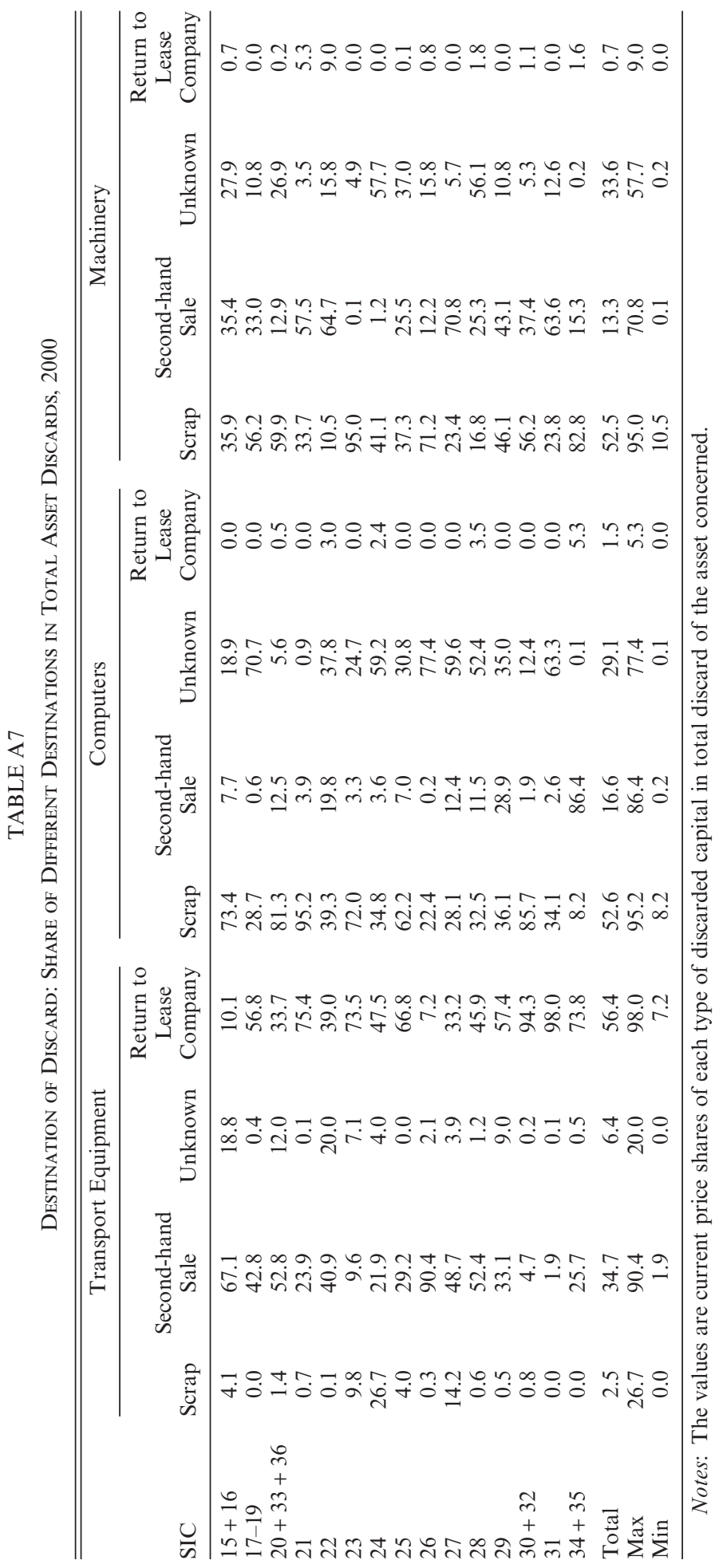

(C) 2008 The Author Journal compilation (C) International Association for Research in Income and Wealth 2008 


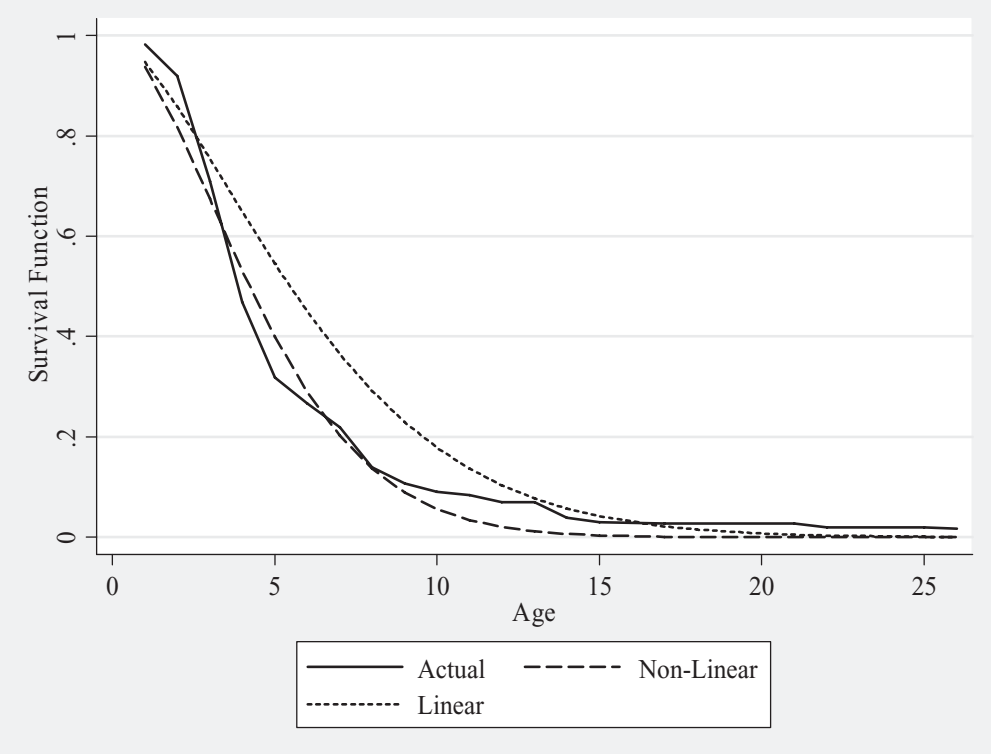

Figure A1. Linear vs. Non-Linear Estimation of Survival Function: Transport Equipment in Industry Printing and Publishing

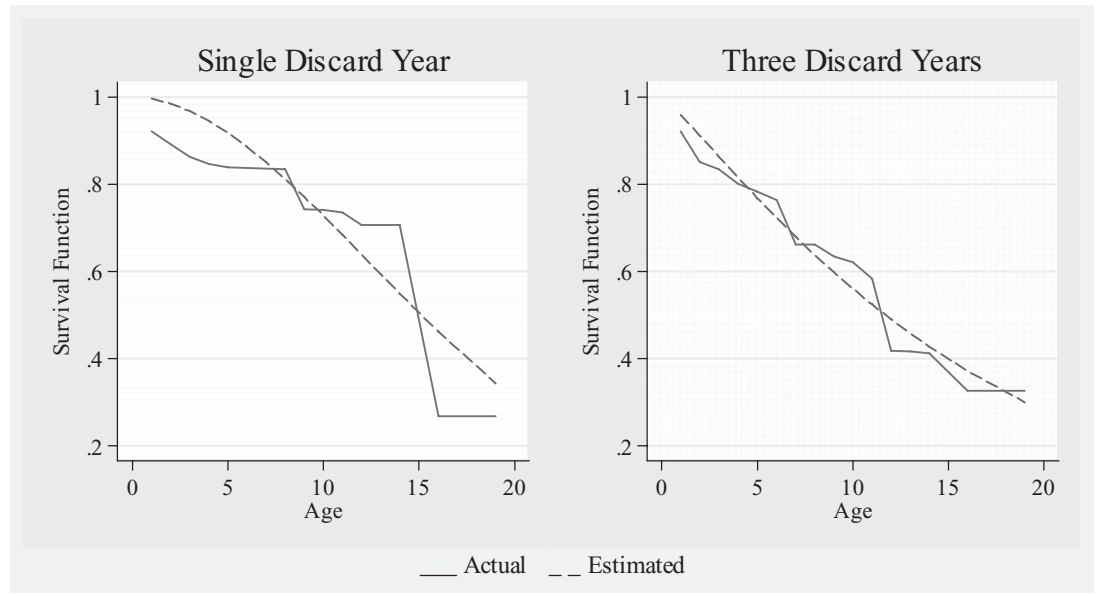

Figure A2. Actual vs. Estimated Survival Function Using Single Year and Three Years Discard Information: Computers in Industry Petroleum, Cokes and Nuclear Fuel 


\section{REFERENCES}

Baldwin, J., G. Gellatly, M. Tanguay, and A. Patry, "Estimating Depreciation Rates for the Productivity Accounts," OECD, http://www.oecd.org/dataoecd/61/22/35409605.pdf, 2005.

Bekker, P. C. F., A Lifetime Distribution Model of Depreciable and Reproducible Capital Assets, University of Amsterdam, 1991.

Bergen, D., M. de Haan, R. De Heij, and M. Horsten, "Measuring Capital in the Netherlands, StdlNaes, 8, OECD, 2005.

Biørn, E., E. Holmøy, and Ø. Olsen, "Gross and Net Capital, and the Form of the Survival Function: Theory and Some Norwegian Evidence," Review of Income and Wealth, 35(2), 133-49, 1989.

Bureau of Economic Analysis, U.S. Department Of Commerce, Fixed Assets and Consumer Durable Goods in the United States, 1925-97, U.S. Government Printing Office, Washington DC, 2003.

Bureau of Labor Statistics, "Overview of Capital Inputs for the BLS Multifactor Productivity Measures," http://www.bls.gov/mfp/mprcaptl.htm, accessed June 6, 2006.

Coen, R., "Investment Behaviour, the Measurement of Depreciation and Tax Policy," American Economic Review, 65, 59-74, 1975.

Denison, E. F., "Some Major Issues in Productivity Analysis: An Examination of Estimates of Jorgenson and Griliches," Survey of Current Business, 49(2), 1-27, 1969.

- Trends in American Economic Growth, 1929-1982, Brookings Institution, Washington DC, 1985.

Erumban, A. A., "Rental Prices, Rates of Return, Capital Aggregation and Productivity: Evidence from EU Countries," Paper presented at the 22nd Annual Meeting of the European Economic Association and the Econometric Society (EEA/ESEM), Budapest, August, 2007.

Fraumeni, B. M., "The Measurement of Depreciation in the U.S. National Income and Product Accounts," Survey of Current Business, July, 7-23, 1997.

Goldsmith, R. W., "A Perpetual Inventory of National Wealth," Conference on Research in Income and Wealth, NBER Studies in Income and Wealth, 14(1143), 5-73, 1951.

Hulten, C. R., "The 'Architecture' of Capital Accounting: Basic Design Principles," Paper prepared for the CRIW conference, A New Architecture for the U.S. National Accounts, April 16-17, 2004.

Hulten, C. R. and F. C. Wykoff, “The Measurement of Economic Depreciation,” in C. R. Hulten (ed.), Depreciation, Inflation and the Taxation of Income from Capital, Urban Institute Press, Washington DC, 1981.

Hwang, J. C., "Forms and Rates of Economic and Physical Depreciation by Type of Assets in Canadian Industries," Journal of Economic and Social Measurement, 28(3), 89-108, 2003.

Jorgenson, D. W., "Capital as a Factor of Production," in D. W. Jorgenson and R. Landau (eds), Technology and Capital Formation, MIT Press, Cambridge, 1-35, 1989.

Jorgenson, D. W. and Z. Griliches, "The Explanation of Productivity Change," Review of Economic Studies, 34, 249-83, 1967.

- "Issues in Growth Accounting: A reply to Edward F. Denison," Survey of Current Business, 52(5), Part 2 (May), 65-94, 1972.

Lock, J. D., "Measuring the Value of the Capital Stock by Direct Observation," Review of Income and Wealth, 31(2), 127-38, 1985.

Meinen, G. W., "Lives of Capital Goods," Paper presented at the 2nd meeting of the Canberra Group on Capital Stock Statistics, OECD, Paris, 1998.

Meinen, G. P., P. Verbiest, and P. P. de Wolf, "Perpetual Inventory Method, Service Lives, Discard Patterns and Depreciation Methods," Canberra Group on Capital Stock Statistics, September, 1998.

Mudholkar, G. S., D. K. Srivastava, and G. D. Kollia, "A Generalization of the Weibull Distribution with Applications to the Analysis of Survival Data," Journal of American Statistical Association, 91, 1575-83, 1996.

Nomura, K., "Examination of Directly Observed Discard Data in Japan," KEO Discussion Paper No. 99, 2005.

OECD, Measuring Capital-A Manual on the Measurement of Capital Stocks, Consumption of Fixed Capital and Capital Services, OECD, Paris, 2001.

Oulton, N., "Depreciation, Obsolescence and the Role of Capital in Growth Accounting," Bulletin of Economic Research, 47(1), 21-33, 1995. , "Productivity versus Welfare; or GDP versus Weitzman's NDP," Review of Income and Wealth, 50(3), 329-55, 2004.

Pitman, J., Probability, Springer-Verlag, 1992. 
Schreyer, P., W. E. Diewert, and A. Harrison, "Cost of Capital Services and the National Accounts," paper presented at the Fifth Meeting of the Canberra II Group on the Measurement of NonFinancial Assets, Canberra, March 29-April 1, 2005.

Smeets, H. H. and N. H. L. van den Hove, Disinvestments, Statistics Netherlands, Voorburg, 1997. Verbeek, M., A Guide to Modern Econometrics, Wiley, 2004.

West, P., "The Direct Observation of Asset Lives," paper for the 2nd meeting the Canberra group on capital stock statistics, Canberra, 1998. 